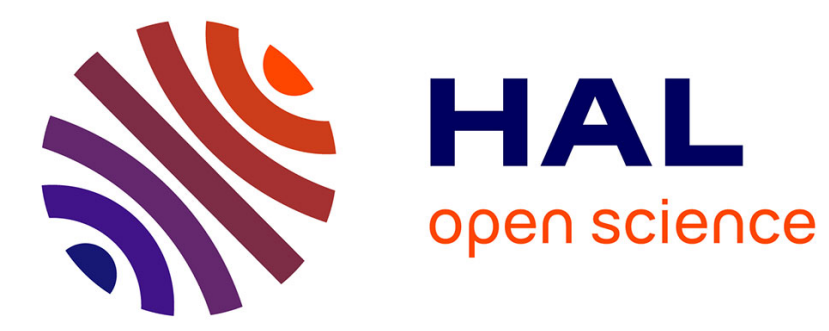

\title{
Predicting US banks bankruptcy: logit versus Canonical Discriminant analysis
}

Zeineb Affes, Rania Hentati-Kaffel

\section{To cite this version:}

Zeineb Affes, Rania Hentati-Kaffel. Predicting US banks bankruptcy: logit versus Canonical Discriminant analysis. 2016. halshs-01281948

\section{HAL Id: halshs-01281948 \\ https://shs.hal.science/halshs-01281948}

Submitted on 3 Mar 2016

HAL is a multi-disciplinary open access archive for the deposit and dissemination of scientific research documents, whether they are published or not. The documents may come from teaching and research institutions in France or abroad, or from public or private research centers.
L'archive ouverte pluridisciplinaire $\mathbf{H A L}$, est destinée au dépôt et à la diffusion de documents scientifiques de niveau recherche, publiés ou non, émanant des établissements d'enseignement et de recherche français ou étrangers, des laboratoires publics ou privés. 


\section{Documents de Travail du \\ PANTHEON SORBONNE Centre d'Economie de la Sorbonne}

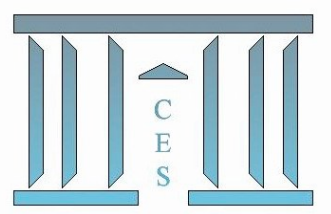

\section{Predicting US banks bankruptcy: logit versus Canonical Discriminant analysis}

Zeineb AFFEs, Rania HentATi-KAFFEL

2016.16

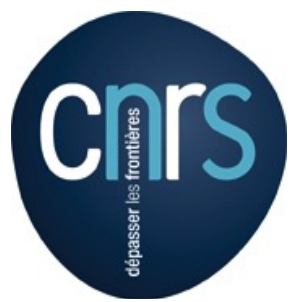




\title{
Predicting US banks bankruptcy: logit versus Canonical Discriminant analysis
}

\author{
Zeineb Affes* $\quad$ Rania Hentati-Kaffel ${ }^{\ddagger}$
}

February 21, 2016

\begin{abstract}
Using a large panel of US banks over the period 2008-2013, this paper proposes an early-warning framework to identify bank leading to bankruptcy. We conduct a comparative analysis based on both Canonical Discriminant Analysis and Logit models to examine and to determine the most accurate of these models. Moreover, we analyze and improve suitability of models by comparing different optimal cut-off score (ROC curve vs theoretical value). The main conclusions are: i) Results vary with cut-off value of score ii) the logistic regression using 0.5 as critical cut-off value outperforms DA model with an average of correct classification equal to $96.22 \%$. However, it produces the highest error type 1 rate $42.67 \%$ iii) ROC curve validation improves the quality of the model by minimizing the error of misclassification of bankrupt banks: only $4.42 \%$ in average and exhibiting 0\% in both 2012 and 2013. Also, it emphasizes better prediction of failure of banks because it delivers in mean the highest error type II $8.43 \%$.
\end{abstract}

Keywords: Bankruptcy prediction, Canonical Discriminant Analysis, Logistic regression, CAMELS, ROC curve, Early-warning system

\section{Introduction}

The financial crisis of 2007 is considered as the first real crisis of excess financial complexity. It illustrates the degree of the existing inter-connectivity between banks and

\footnotetext{
${ }^{*}$ Contact author. Centre d'Economie de la Sorbonne, Université Paris1 Panthéon-Sorbonne, Maison des Sciences Economiques, 106-112 Boulevard de l'Hôpital 75013 Paris, France.Email: zeineb.affes@univparis1.fr

${ }^{\dagger}$ Contact author. Centre d'Economie de la Sorbonne, Université Paris1 Panthéon-Sorbonne, Maison des Sciences Economiques, 106-112 Boulevard de l'Hôpital 75013 Paris, France. Phone: 003314407 87 45, Email: rania.kaffel@univ-paris1.fr

${ }^{\ddagger}$ This work was achieved through the Laboratory of Excellence on Financial Regulation(Labex ReFi) supported by PRES heSam under the reference ANR-10-LABX-0095.
} 
financial institutions and highlighted the phenomenon of contagion that might exist in the interbank market. Since then, a swarming literature has been developed on the subject of quantification, prediction and control of systemic risk.

One of the methods proposed to prevent contagion of bank failures is to assess the bank failure rate. This approach helps to establish an early warning model of bank difficulties. Thus, interactions that may exist between solvency and refinancing risk can identify the banks which have the most difficulties to refinance and therefore be perceived as risky by the other institutions. This stigma will limit part counterparty risk and warn the financial authorities of a liquidity risk in case of default of these banks.

The existing financial literature engorges methods and models which aim to identify institutions whose financial situation appears alarming and deserves attention by supervisors. In this study, we propose to estimate and test the effectiveness of forecasting models of bank failures in the United States. The specificity of our study lies in the fact that it takes into account several financial ratios (solvency ratios, quality of assets, cash or liquidity ...) and is based on a very large sample of US banks (large and small bank) and from 2008 to 2013. The results of our study confirm that early warning system of banking difficulties including CAMEL financial variables is of great efficacy.

The empirical literature distinguishes two methods: parametric and non-parametric validation.Beaver (1966) was the pioneer in using a statistical model for predicting bankruptcy. The approach is to select from thirty financial ratios those which are the most effective indicators of financial failures. The study concludes that the (cash flow/Total debt) ratio is the best forecasting indicator.

Altman (1968) tested Multiple Discriminant Analysis (MDA) to analyze 70 companies, first by identifying the best five significant explanatory variables from a list of 22 ratios and then by applying the (MDA) to calculate a Z-Altman score for each company. This score was almost accurate in predicting bankruptcy one year ahead. This model was then subsequently improved in Altman and Narayanan (1997) by proposing the zeta model that includes seven variables and classified correctly $96 \%$ of companies one year before bankruptcy and $70 \%$ five years before bankruptcy.

Since then, the use of discriminant analysis has continued to grow through the different published studies (Bilderbeek (1979); Ohlson (1980); Altman (1984):Zopounidis and Dimitras $(1993) \ldots)$. The vast majority of studies achieved after 1980 used the logit models to overcome the drawbacks of the DA method (Zavgren (1985); Lau (1987); Tennyson et al. (1990)...) The logit analysis fits linear logistic regression model by the method of maximum likelihood. The dependent variable(the probability of default) gets the value "1" for bankrupted banks and "0" for the healthy banks.

The second main approach has been developed to fix the constraints of traditional statistical model. Non parametric methods such TRA (Trait Recognition Analysis) also called Trait Recognition Models (TRM) has no prior assumption about variables to predict. It is associated to neural network models and allows the information exploration when interactions between the independent variables are nonlinear (Kolari et al. (2002)). In this sense, since (Frydman et al., 1985) work, decision tree has become a popular data mining technique and commonly used for classification and prediction. 
Many other studies have applied this same technique in commercial US banks and have shown that it performs better than the Probit model (Marais et al. (1984)). Messier Jr and Hansen (1988) show that inductive algorithm is better than the DA.

Numerous comparative studies were carried out (Keasey and Watson (1991); Dimitras et al. (1996)); Altman and Narayanan (1997); Wong et al. (1997); Adya and Collopy (1998); O'leary (1998):Zhang et al. (1998); Vellido et al. (1999); Coakley and Brown (2000); Aziz and Dar (2004); Balcaen and Ooghe (2006); Balcaen et al. (2004); Kumar and Ravi (2007)). However, the supremacy of one method over another remains subject to various controversies because of the heterogeneity of the data used for validation (database, number of points in the data, sample selection, validation methods for forecasting, the number and the nature of explanatory variables tested in the model (financial, qualitative ...).

However, recent studies have shown the superiority of neural networks over other techniques (Du Jardin (2010); Jo et al. (1997); Tsai and Wu (2008)). In particular, Du Jardin (2010) results, based on over 200 previous articles, showed that neural network based model leads to better results in terms of failure rate prediction.

The aim of this paper is twofold: descriptive and predictive. In the financial literature, the analytical part is often not addressed. Nevertheless, we believe that this is the cornerstone of a better interpretation of the results. Thus, we proceed by describing and analyzing key financial ratios of the active and non-active banks for the entire period from 2008 to 2013.

In this paper we combined three parametric models (Canonical Discriminant Analysis and Logit) with the descriptive Principal Component Analysis model (PCA) to construct an early warning system (EWS).

First, (PCA) reduced the size of data (dimension below 10) and insure an uncorrelated blend of variables framework. Then, factor scores were estimated for each bank. These scores were used to estimate (CDA) and Logit models.

One among the important results of this paper is to have compared several methods to calculate the theoretical value of the probability of default that will serve as threshold to split the bank universe into two set : failed or healthy.

The paper consists of four sections. After the introduction, an overview of the existing literature concerning the bank failure prediction is given. Section two describes used data, the methodology and (PCA) results. Section three provides the empirical analysis and the study results. Finally section four contains concluding remarks.

\section{Description of the Methodology and the variables}

This section focuses on the data gathered for the estimation of our models. We begin by describing data collection and variables selection process. Next, we present the financial and economic ratios followed by descriptive statistics and correlation analysis. 


\subsection{Data description}

We proceed to the constitution of our database of US banks from mainly two sources: "BankScope" and FDIC. Our database covers the period 2008-2013. Statistics shows that the period from 2008 to 2013 is marked by a wave of bank failures in the United States: more than 450 bank failures and FDIC estimated losses to more than US 85 billion dollar.

After data reprocessing, the sample banks contains two categories: active banks and non-active banks. Non-active banks are those which have been declared as bankrupted by the Federal Deposit Insurance Corporation (FDIC). The information on the identity and the bank's balance sheet data are obtained from the FDIC website. Indeed, all US banks must report their financial statements in the Uniform Bank Performance Report. Some treatments have been applied to our sample to allow homogeneity between banks. Indeed, a bank that has been declared bankrupted in the first quarter of the year "N" will be reclassified and considered as bankrupted in late "N-1"

For banks declared bankrupt by the FDIC after 01/04/N and for which there is no information for the current year, they will be considered as inactive for the year "N". For banks that will make bankruptcy at date later and which data are available in $31 / 12 / \mathrm{N}$, they will be considered as active for "N". Financial variables of active banks were retrieved from the database "BankScope". Data were available for only 928 banks each year in the period 2008-2013. After processing and verifying data availability of the financial statements required in our study, the number of banks was reduced to 411 failed banks over the entire period 2008-2013 and 836 active banks each year. Table 1 gives more details on our database.

\subsection{Variables: review of the literature}

Federal regulators developed the numerical CAMEL rating system in the early 1970s to help structuring their examination process. This rating is based on the capital adequacy, asset quality, management quality, earnings ability, and liquidity position ratios. Capital adequacy evaluates the quality of a bank's capital. Asset quality measures the level of risk of a bank's assets. This is reflects the quality and the diversity of the credit risk and the ability of the bank to repay issued loans. Management quality is a measure of the quality of a bank's officers and the efficiency of its management structure. Earnings ability reflects the performance of banks and the stability of its earnings stream. Liquidity measures the ability of banks to meet unforeseen and unexpected deposit outflow in the short time. In February 1997, a sixth component sensitivity to market risk was added to the CAMEL rating system.

A very abundant literature tried to identify the most significant variables of the financial health of banks. According to Sinkey (1975), the quality of bank assets is the most significant ratio. Assets composition, loans characteristics, capital adequacy, source and use of income, efficiency and profitability are also discriminant variables. Poor asset quality and low capital ratios were the two characteristics of banks most consistently associated with banking problems during the 1970s (Sinkey (1978)). Avery et al. (1984), 
Barth et al. (1985) and Benston (1985) conclude that the proxies of loans portfolio composition and quality, capital ratio and the source of income are significant. Thomson (1991) demonstrate that the probability that a bank will fail is a function of variables related to its solvency, including capital adequacy, asset quality, management quality, and the relative liquidity of the portfolio. Martin (1977) found that the capital asset ratio, and the loans portfolio's composition to total assets ratio have a high level of significance. Pantalone et al. (1987) proposed a model including most of CAMEL proxies: profitability, management's efficiency, leverage, diversification and economic environment. Their results confirm the main cause of default was bad credit risk management. The model of Barr et al. (1994) include CAMEL proxies and efficiency scores as management's quality proxies and a proxy of the economic conditions. The six variables selected for their failure-prediction models are equity/total loans (C), non performing loans/total assets (A), DEA efficiency score (M), net income/ total assets (E) and large dollar deposits/ total $\operatorname{assets}(\mathrm{L})$.

Our main objective in this study is to provide an accurate bank failure model based on the significant fragility factors. In line with the literature, we maintain the most commonly used financial ratios which can forecast potential failures (Beaver (1966), Altman (1968)), Thomson (1991), Kolari et al. (1996), Jagtiani et al. (2003), Dabos and Sosa-Escudero (2004), and Lanine and Vander Vennet (2006)).

\section{Principal Component Analysis}

\subsection{Variable's Statistics description}

We include in our analysis four categories of variables: (1) two measures of capital adequacy. These latter indicates the measurement of the financial strength of a bank and determines the capacity of the bank in terms of meeting time liabilities and other risk such as credit risk, market risk, operational risk and others. The most popular proxy for capturing capital adequacy in previous literature is total equity divided by either total assets or total loans. (2) assets quality measures are considered in data construction. These variables have a crucial role in the assessment of the current condition and financial capacity in the future. We employ four variables related to asset quality (NPLTA, NPLGL, LLRTA, and LLRGL). We note that for NPLTA and NPLGL variables we use the proxy loans not accruing plus loans over 90 days late/ total assets (non-performing loans/total assets). (3) Bank profitability which is assessed through two ratios. The first ratio is the net profit as a share of total assets. As for the second measure, it is the net profit as a share of total shareholders' equity. Both measures are positively related to the financial performance of the bank and negatively related to the failure (Hassan Al-Tamimi and Charif (2011)). (4) The liquidity level of the bank is assessed through employing three ratios. The first one is total liquid assets to total assets. This indicates the ability of the bank to cover its liabilities. The second ratio which was used to estimate liquidity is total liquid assets as a share of total deposits. This ratio depicts the capacity of the bank to cover unanticipated deposit withdrawal. The ratio 
of liquid assets to short term liabilities is the last ratio to determine the liquidity. The explanatory variables are shown below:

\begin{tabular}{ccc}
\hline Categories CAMEL & Variables & Definition \\
\hline Capital Adequacy & EQTA & Total Equity/Total Assets \\
& EQTL & Total Equity/Total Loans \\
\hline Assets Quality & NPLTA & Non Performing Loans/Total Assets \\
& NPLGL & Non Performing Loans/Gross Loans \\
& LLRTA & Loan Loss Reserves/Total Assets \\
& LLRGL & Loan Loss Reserves/Gross Loans \\
\hline Earnings Ability & ROA & Net Income/Total Assets \\
& ROE & Net Income/Total Equity \\
\hline Liquidity & TLTD & Total loans /Total customer Deposits \\
& TDTA & Total Customer Deposits/Total Assets \\
\hline
\end{tabular}

Table (2) presents the means of the ten financial ratios for the two groups (Non Failed Bank (NFB) and Failed Bank (FB)), and significance tests for the equality of group means for each ratio.

First, according to capital adequacy ratios which are measures of how much capital is used to support the banks' risk assets. (EQTA) ratios for (FB) are on average very low. A low ratio means a significant leverage of these banks. This makes banks less resistant to shocks. Thus, the higher (EQTA) value is; the lower the probability of default will be. As banks trend toward failure, their equity position is likely to decrease, thus a negative relationship is expected between total loans and failure. The same conclusions emanate from the (EQTL) ratio analysis.

According to the asset quality ratio, we note that (NPLTA) ratios for (FB) are very low and disparate for the period spanning between 2008 and 2013. The immediate consequence of large amount of non-performing loans(NPL) is bank failure. In fact, according to our data, the economic environment has pushed up (NPL) thus the ratios (NPLTA), (NPLGL), (LLRTA) and (LLRGL) decrease. Banks with a high (NPL)amount tend to carry out internal consolidation to improve the asset quality rather than distributing creditand will be obliged to raise provision for loan loss. For example, (NPLGL) ratio fell by $3.92 \%$ from $13.35 \%$ to $9.31 \%$ for (FB) and by $1.17 \%$ for (NFB). We note that low value of loan portfolio signals the potential existence of an important vulnerability in the financial system (17.75\% in 2008 and $17.83 \%$ in 2010). (LLRTA) and (LLRGL) provide an useful indication for analysts because they indicate a bank's sense of how stable its lending base is. The higher the ratio, the poorer the quality of the loan portfolio will be (3.59\% for (LLRTA) ratio and $5.17 \%$ for (LLRGL) ratio for the (FB) in 2011).

Finally (TLTD) and (TDTA) liquidity ratios are often used by policy makers to assess the lending practices of banks and get some statistics. If the ratio is too high, it means that banks might not have enough liquidity to cover any unforeseen fund requirements; if the ratio is too low, banks may not be earning as much as they could be. Table (2) 
exhibits in average for(FB) high values (for example $91.13 \%$ and $82.63 \%$ for 2008 and 2009). These high ratios reflect the fact that they are relying on borrowed funds.

Table (3) is used to analyze the correlation coefficients between the different explanatory variables and the dependent variable (probability of default). We note the significance at $1 \%$ and $5 \%$ of all the variables that we have retained in our study. Note also that most of the coefficients have the expected signs. For example, a negative correlation is confirmed for (EQTA) and (EQTL) for all years. Indeed, an increase in the value of the two ratios has a negative effect on the bank's survival.

Table(4), presents the correlation matrix of ratios. Here, it can be seen that most of the ratios shows correlation to each other. When scrutinizing the correlation's matrix pairwise, we can distinguish the following aspects. There is a strong correlation (over $90 \%$ ) between the pairs of variables (NPLTA) / (NPLGL) and (LLRTA)/(LLRGL). This result is generalized for all years and reflects a strong link between them and that one of the variablescan be replaced by another.Also, the Asset quality component (AQ) which groups (NPLTA), (NPLGL), (LLRTA) and (LLRGL) variables is negatively correlated with the return on assets (ROA). The ratio (EQTA) variable, which is a proxy of capital adequacy, and profitability of assets are negatively correlated with proxies of asset quality. There is a positive correlation between asset quality and profitability of the bank's assets. The same interpretation is still valid for years 2010 and 2011.

\section{$3.2 \quad$ PCA}

In this section we present the results of variables selection under the Principal Component Analysis (PCA). The aim is to extract the most important information from the data and to compress the data dimension by keeping only the most important ratios to explain the changes in financial conditions of banks.

Several tests are provided as following:

i) Bartlett's test to validate the assumption of equality of variances. In this sense, if the test statistic is larger than the critical value, we reject the null hypotheses at the $5 \%$ significant level (Table 5). Thus, the sample correlation matrix did not come from a population where the correlation matrix is an identity matrix.

ii) Kaiser-Meyer-Olkin (KMO) to test if the variables have enough in common to warrant a factor analysis. In this test (KMO) retain only components with eigenvalues greater than one. Eigenvalues, also called characteristic roots are presented in Table (5).

In addition to this tests, we perform (PCA) by analysing Factor Loading which are correlation coefficients between the financial variables and factors. Finally, we determine the (PCA) scores.

Before getting to the description of (PCA), we first analyse the correlation matrix. Then after centering and standardizing each ten variables, we determine the optimal number of principal component analysis. 
The starting point is the correlation matrix. Table (4) presents the degree of dependence between the initial ten variables. It can be easily seen that variables are correlated. This means that the information they convey have some degree of redundancy. To perform this finding of correlation, we present in Table (5) Bartlett's test of Sphericity. Bartlett test compares the correlation matrix with a matrix of zero correlation. A zero p-value is obtained over all the period from 2008 to 2013. Thus, we perform a valid factor analysis.

Table (6) describes the estimated factors and their eigenvalue. In 2008, we retain the first three factors. These factors explain $71.93 \%$ of the total variation of the financial conditions of banks. The first factor is the most important dimension to explain the changes in financial conditions of banks. It explains $41.54 \%$ of the total variance of the selected financial ratios. Factors F2 and F3 respectively explain $16.15 \%$ and $14.23 \%$ of the total variance.

Under the same decision rule of (KMO) measure and based on the results of the Eigenvalue's factors of 2009 . These four factors account for $81.76 \%$ of the total variation of the financial conditions of banks. The first factor explains $46.81 \%$ of the total variance of financial ratios. Factors F2, F3 and F4 respectively explain 13.23\%, 11.56\% and $10.15 \%$ of the total variance.

In 2010, the first three factors explained $71.4 \%$ of the total variation. The first factor explains $46.6 \%$ of the total variance. Factors F2 and F3 respectively explain $13.9 \%$ and $10.89 \%$ of the total variance. The choice of four factors is validated for 2011 and account for $81.68 \%$ of total variation. Finally, for the years 2012 and 2013, the first four selected factors explain almost $77 \%$ of the total variation.

We follow (PCA) by considering and evaluating Factor's loadings (see Table 7). In our case, the contribution ratios in the main components vary between 0 and 1 in absolute values. If a variable contributes more than 0.5 in a specific factor, it will be considered as the main indicator. However,if its contribution is below this threshold, the variable will be considered as a secondary indicator.

For 2008, variables that explain better the first factor F1 are (NPLTA), (NPLGL), (LLRTA), (LLRGL) and (ROA). F1 refers to both assets quality and return on assets components. The component loadings tell us how much of the variation in a variable is explained by the component. For example asset quality loading values are negatives. Thus, an increase in the value of these ratios will result in a lower score factor F1. So, the increase in these ratios will decline the asset quality. This implies, subsequently, an increase in the probability of default of the bank. The (ROA) ratio has a positive loading, which means that an increase in its value will increase the F1 score. We find the same results for 2009, 2010 and 2011 for F1 factor. For 2012 and 2013, F1 groups only variables of asset quality. For 2013, all the ratios have a positives loadings, which means that an increase in its values will increase the score of the factor F1.

F2 groups ratios of Capital Adequacy (EQTA) and (EQTL) only for 2008, 2012 and 2013. Loadings for these two variables are positives. An increase in the value of these two ratios will increase the value of the score of the Capital Adequacy factor and reduce the probability of default. 
In 2009 this factor is composed by the ratios (TLTD) and (TDTA). Loadings are negatives and an increase of the value will accentuate the probability of default.

In 2010 and 2011, we retain also the second factor F2 which includes liquidity components. (TLTD) ratio has a positive loading, which means that an increase in its value will increase the D-score of the liquidity factor. (TLTD) ratio is considered as a good proxy of short term viability and a low value means that there is no optimal reallocation of resources.

For 2009, 2010 and 2011 the factor F3 is composed by capital adequacy variables and (TDTA) variable.

For the other years studied, a fourth factor (F4) is considered and it brings the ratio (ROE) and the two ratios of asset quality.

Finally, we determine the factor score coefficient matrix for each bank. According to the Table (8) which describes the factor score coefficients, we calculate factor scores for each bank using the formula below:

$$
F_{b i}=\sum u_{i j} z_{b j}
$$

Where:

- $\mathrm{F}_{b i}$ :the estimated factor i for bank $\mathrm{b}$

- $\mathrm{z}_{b j}$ : the standardized value of the jth ratios for a bank $\mathrm{b}$

- $\mathrm{u}_{i j}$ : the factor score coefficient for the ith factor and the jth ratios

- These scores $\left(\mathrm{F}_{a i}\right)$ were used as independent variables in estimating the discriminant and the Logit model.

\section{Empirical results}

\subsection{Canonical Discriminant Analysis}

In this section, we provide Canonical Discriminant Analysis (CDA) to conduct and recuperate an early warning system indication of failed banks. In this sense, we propose to describe the relationships among the two groups of banks (bankrupt or not) based on a set of discriminating variables.

The canonical discriminant function is expressed as follow:

$$
D_{b i}=b_{0}+\beta_{1} F_{b 1}+\beta_{2} F_{b 2}+\ldots+\beta_{i} F_{b i}
$$

Where:

- $\mathrm{D}_{b i}$ : the value (score) on the canonical discriminant function for bank $\mathrm{b}$.

- $\mathrm{F}_{b i}$ : represents factors validated in $(\mathrm{PCA})$ section. 
Each sampling group of bank has a single composite canonical score, and the group centroids indicate the most typical location of a bank from a particular group. Discriminant analysis assumes the normality of the underlying structure of the data for each group. The proposed procedure is as follow:

1. Estimate the D-score of each bank via the equation ??

2. Calculate the cut-off score.

3. Classify banks according to the optimal cut-off.

We recall that the optimal cut-off score is approximately zero. This is the weighted average of scores for bankrupt banks and active banks. Thus, the decision rule applied in the separation of sample studied is: a bank with a D-score less than zero will be considered as a bankrupt bank. However a bank with a D-score greater than zero will be classified in the group of healthy banks.

Eigenvalue's for 2008, 2009 and 2013 are respectively $0.2389,0.4626$ and 0.4775 (see Table 9). This result shows that the discriminant function does not allow easy identification of status between banks. Statistics of Wilk's lambda which correspond to the total variance in the discriminant scores not explained by differences among the groups confirm this result. Wilk's values for 2008, 2009 and 2013 are respectively $80.72 \%$, $68.37 \%$ and $67.68 \%$ of the variance are not explained by group differences.

For 2012, a high eigenvalue (0.8013) shows that the discriminant function differentiates the two groups of banks. The model explains only $44.49 \%$ (Square canonical R) of the variance between the two classes (FB, NFB). Wilk's lambda greater in average than $70 \%$ shows that the most of total variability is attributable to differences between the means of D-scores of the groups. The square canonical correlation coefficient testifies the weak association between the discriminant scores and the set of independent variables (among 35\%).

Finally, the linear combination of the factors scores provide for each bank a D-score, according to the estimated canonical discriminant model below :

$$
\begin{aligned}
& D_{\text {score } 2008}=0.9550 F_{1}+0.3071 F_{2}+0.2059 F_{3} \\
& D_{\text {score } 2009}=0.8921 F_{1}-0.2337 F_{2}-0.6026 F_{3} \\
& D_{\text {score } 2010}=0.9217 F_{1}+0.2594 F_{2}-0.5791 F_{3} \\
& D_{\text {score } 2011}=0.9536 F_{1}+0.2449 F_{2}-0.5198 F_{3} \\
& D_{\text {score } 2012}=0.8876 F_{1}+0.5917 F_{2}+0.5595 F_{4} \\
& D_{\text {score } 2013}=-0.8190 F_{1}+0.3770 F_{2}+0.4593 F_{3}+0.5229 F_{4}
\end{aligned}
$$

Correlations between predictor variables and standardized canonical discriminant function are given in the table 10 .

Over all there are no surprises in score's factors. In 2008 for example, F1, F2 and F3 are positively related to the D-score's bank. Clearly, good asset quality and a high level 
of equity, improve profitability. In addition, a sufficient level of liquidity help bank to be able to perform its score and its ranking so it promotes in the non-failed bank group. In 2009, according to the structure of the matrix correlation (see Table 10) we retain only 3 Factors. F2 and F3 are negatively related to the score. This means that the rise of these later will reduce the bank's score. Indeed, a low level of liquidity coupled with a low level of funds reduces the bank's score.

\subsection{Logit Regression}

In this section, we propose the validation of the logit model which is considered as one of the most commonly applied parametric failure prediction models in both the academic literature as well as in the banking regulation and supervision. Logit model is based on a binomial regression and is based on the estimation of the probability of failure $\mathrm{P}(\mathrm{Z})$. This probability is defined as a linear function of a vector of covariates $\mathrm{Z}_{i}$ and a vector of regression coefficients $\beta_{i}$ :

$$
Z_{i}=\beta_{0}+\beta_{1} X_{1}+\beta_{2} X_{2}+\ldots+\beta_{n} X_{n}
$$

In this study, the logistic regression model used, the dependent variable $Y_{i}$ Which takes a value of $1(Y=1)$ when a failure occurred in a predefined period following the date at which the financial statement data are determined. If not, $Y_{i}$, takes on a value of $0(Y=0)$ when no failure occurred.

The relationship between the dependent variable and the predictor variables is expressed as follows:

$$
\left\{\begin{array}{c}
P(Y=1)=P(Z)=\frac{1}{\left(1+\exp ^{(-Z)}\right)} \\
P(Y=0)=1-P(Z)=\frac{1}{\left(1+\exp ^{(Z)}\right)}
\end{array}\right.
$$

In our analysis we consider the factors determined from the (PCA) as explanatory variables. After estimating the coefficients of the Logit model, we obtain the score of each bank $Z_{a}$ :

$$
Z_{a}=\beta_{0}+\sum_{i=1}^{n} \beta_{i} F_{i}
$$

Subsequently, we determine the probability of default of each bank:

The estimated probability of default allows the reallocation of each bank to a specific risk class. Subsequently, a threshold $\mathrm{P}^{*}$ is set to enable segregation between banks and the allocation of these to one of two classes. If the estimated default probability is greater than $\mathrm{P}^{*}$ then the bank will be considered bankrupted, conversely, if the estimated default probability is lower than $\mathrm{P}^{*}$, it will be considered active. Most previous work considers a bank as faulty if its default probability is greater than or equal to 0.5 . 


$$
\begin{aligned}
& Z_{\text {score } 2008}=-6.5238-0.245 F_{1}-3.0669 F_{2} \\
& Z_{\text {score } 2009}=-4.0591-0.6651 F_{1}+2.1396 F_{3} \\
& Z_{\text {score } 2010}=-4.9435-0.8357 F_{1}+2.7505 F_{3} \\
& Z_{\text {score } 2011}=-7.7326-1.1374 F_{1}+3.6381 F_{3} \\
& Z_{\text {score } 2012}=-7.5883-0.7508 F_{1}-2.1392 F_{2}-1.4157 F_{3}-0.6151 F_{4} \\
& Z_{\text {score } 2013}=-8.2816+0.4643 F_{1}-3.1646 F_{2}-0.3756 F_{3}
\end{aligned}
$$

For 2008, only F1 and F2 are significant with a value of $R^{2}$ equal to $50.72 \%$. For 2009 , the level of $R^{2}$ is relatively low (47\%) and only F1 and F3 are significant. In general, we found the same results for 2010 and 2011. For 2012, the model is very satisfactory with $R^{2}$ value close to $75 \%$. All factors are significant. For the last year, the quality of the regression is good. All of F1, F2 and F3 are significant at the 5\% level.(Table 11, Table 12)

For 2008 and 2012, all the significant factors are negatively related to the score of the bank. This means that an improvement in the asset quality, a better profitability, a high level of equity and a sufficient level of liquidity will increase the score of the bank and reduce the probability of default.

For 2009, 2010 and 2011, the factor F3 was positively related to the score. In fact, a low level of equity increases the probability of default of the bank. For 2013, factor F1 is positively related to the score, meaning that the rise of this factor (bad asset quality) will penalize the bank with a high probability of default. To sum up, all variables (ratios) have the expected signs.

\subsection{Evaluation of the models}

To evaluate the prediction performance of DA and Logit models, we consider type I/II error rates. They can be measured by a confusion matrix shown in Table 13. This matrix summarizes the correct and incorrect classifications that models produced for our dataset. Rows and columns of the confusion matrix correspond to the true and predicted classes respectively. The error type I is the error of not rejecting a null hypothesis when the alternative hypothesis is the true state of nature. This latter concern the prediction error of the classifier which incorrectly classifies the bankrupted bank into nonbankrupted bank. Thus, error type II presents the rate of prediction errors of a classifier to incorrectly classify the non-bankruptcy bank into bankrupted bank. As consequence, a natural criterion for judging the performance of a classifier is the probability for making a misclassification error.

We consider an early warning model as good when it delivers a low probability of committing error Type I and avoid classifying a failed bank in to the group of nonbankrupted banks.

For the prediction accuracy of the (CDA) model we proceed by two approaches to select the best cut-off score. 
In the first one, we calculate the cut-off score.

In literature and according to Canbas et al. (2005), the default cut-off value in two class classifiers is approximately equal to zero and computed by the equation below:

$$
C u t-O f f=\frac{\left(N_{1} D_{1}+N_{0} D_{0}\right)}{\left(N_{1}+N_{0}\right)}
$$

Where

- $\mathrm{N}_{1}$ :number of bankrupted bank

- $\mathrm{D}_{1}$ :average score for bankrupted bank

- $\mathrm{N}_{0}$ :number of non-bankrupted bank

- $\mathrm{D}_{0}$ :average score for non-bankrupted bank

But, if the two classes are asymmetric and unequal in term of size, the optimal cutting score for a discriminant function is the weighted average of the group centroids Hair et al. (2010). The formula for calculating the critical score between two groups is:

$$
C u t-O f f=\frac{\left(N_{A} Z_{B}+N_{B} Z_{A}\right)}{\left(N_{A}+N_{B}\right)}
$$

Where $\mathrm{Z}_{A}$ and $\mathrm{Z}_{B}$ are the centroids for group $\mathrm{A}$ and $\mathrm{B}$ and $\mathrm{N}_{A}$ and $\mathrm{N}_{B}$ are the number of banks in each group. This formula is adopted in our paper for the (CDA) analysis. The second methodology to select the optimal cutting score is based on the Receiver operating characteristics (ROC curve) graphs.

After, we classify bank in failed or healthy group according to the comparison between D-score and the cut-off score:

- if D-score > cut-off, the bank is classified to the non bankrupt group

- if D-score < cut-off, the bank is classified to the bankrupted group

From the results in tables 14 and 17, we can observe that the average correct classification rate is about $90 \%$. For example, in 2008, the number of miss-classified bankrupt bank is 10 (error type I is equal to $27.03 \%$ ). 79 healthy banks were classified in the FB group (type II error 6.55\%). Looking more closely at our database, we found that among these 79 banks predicted to failing banks, 75 banks will actually fail during the years 2009, 2010 and 2011.

In 2009, type II error is equal to $11.31 \%$. By scrutinizing the state of these banks that are considered by the (CDA) model as bankrupted, we find that they go bankruptcy in the years following. The model is quite severe in its classification and penalizes some 
banks even before they were to fail. The results of the discriminant analysis for the year 2012 were significant. Indeed, the model was able to correctly predict $97.62 \%$ of banks. 10 failed banks were classified in the group of NFB (30.30\% type I error) and 11 healthy banks were allocated to the FB group (1.29\% type II error). Among active banks classified bankrupt, actually seven banks will go bankrupt in the year 2013 .

In 2013, the discriminant function deliver a good rate of $98.82 \%$ ranking. In other words, the model has failed to correctly classify banks $1.18 \%$. Indeed, five failed banks were predicted as active banks (33.33\% type I error) and 5 active banks were allocated to the FB group (type II error $0.6 \%$ ).

To sum up, with the canonical discriminant analysis we obtained good prediction rates of about $92.85 \%, 87.36 \%, 89.99 \%, 93.52 \%, 97.62 \%$ and $98.82 \%$ for respectively 2008, 2009, 2010, 2011, 2012 and 2013 years. We also noted that the type II error rate is relatively high $(6.55 \%, 11.31 \%, 9.2 \%, 5.54 \%, 1.29 \%$ and $0.6 \%$ for the years 2008,2009 , 2010, 2011, 2012 and 2013). This means that some non-failed banks were predicted as failed banks. Therefore, and after analyzing our database, we can conclude that discriminant analysis predicts the failure of banks in the years ahead.

Finally according to the best cut-off obtained via the ROC curve methods, we obtain results in term of accuracy (classification rate), Type I, type II error, sensitivity and specificity which are presented in table 17.

The optimal critical point corresponds to the value which minimizes both the error of the type I (bankrupted banks classified in the group of the non-failed banks) and the error of the type II (active banks classified like failing). It is also the value which makes it possible to maximize sensitivity (correctly classified failing banks) and specificity (active banks correctly assigned to the group of the non-failing banks).

The application of the research of the critical point in the (CDA) model gives the following results: in 2008, according to figures 1 and 2, the optimal threshold is reached at the value of -1.4306 . The discriminating analysis succeeded in classifying $91.72 \%$ of the banks in the adequate groups. Indeed, $86.49 \%$ of the defaulted banks and $91.88 \%$ of the non-failed banks were correctly classified. Among, the 37 failing banks, 32 banks were assigned to the group of the banks in bankruptcy. On the other hand, 5 banks in bankruptcies were classified in the group of the non-failed banks (error type I : 13.51\%). Moreover, 98 active banks were declared like failing banks (error type II was 8.12\%).

In 2009 , the model made it possible to classify $90.83 \%$ of the banks correctly. $77.86 \%$ from the failing banks and $92.4 \%$ of the non-failed banks were correctly classified. According to the confusion matrix, we notice that 29 failing banks were assigned to the group of the healthy banks (error type I was $22.14 \%$ ) and 82 active banks were classified as failing banks (error type II of $7.60 \%$ ).

For the year 2010, the discriminating analysis succeeded in classifying $95.37 \%$ of the banks correctly. Indeed, $84.43 \%$ of the failing banks and $96.76 \%$ of the non-failed banks were assigned to their adequate group. Among the 122 failing banks, 19 banks were classified as non-failed banks (error type I 15.57\%). $3.24 \%$ of the healthy banks were classified as failing banks.

In 2011, the results show an improvement in the rate of good classification (96.87\%). 
Indeed, $91.78 \%$ of the failing banks and $97.29 \%$ of the non-failed banks were correctly classified. Conversely, 6 banks of the failed group were predicted as healthy banks (error type I was $8.22 \%$ ).

In 2012, the best critical point took the value of -1.8593 and made it possible to classify $99.77 \%$ of the banks correctly. Indeed, the discriminating model made it possible to classify all the healthy banks in the group of the non-failed banks (specificity 100\%). Yet, 2 banks among the 33 failing banks were classified in the group of the non-failed banks (error type I 6.06\%).

The same results are observed for the year 2013. With a cut-off of -0.9216 , the rate of correct classification is of $99.76 \%$ and all of the non-failed banks were correctly classified (specificity 100\%).

We can conclude that the Canonical Discriminant Analysis classify correctly on average $95.7 \%$ of banks in the appropriate groups.

In 2008, the Discriminant Analysis was able to classify $91.72 \%$ of banks in the appropriate groups. The results in the following years show an increase in the accuracy of the model. We notice that the rate of the correct classification was improved passing from $91.72 \%$ in 2008 to $99.76 \%$ in 2013. Based on the confusion matrix, we note that the rate of misclassification of the active banks tend to decrease over the years (from $8.12 \%$ in 2008 to $2.71 \%$ in 2011). In addition to that, for the period spanning between 2012-2013 the model classify correctly all active banks (error type II : 0.00\%). The obtained results indicate that the discriminant analysis does not correctly classified bankrupt banks. Indeed, we found that the error Type I rates are relatively high. For example in 2009, 22.14\% failed banks were allocated to active banks group.

The model seems to be very effective for the years 2012 and 2013. The banks were able to clean up their balance sheet and to recover after the crisis (years 2008 and 2009.)

For the prediction accuracy of the Logit model, we Firstly compared the probability of default obtained from the scoring function with the theoretical threshold (probability of default $=0.5$ ). After, we used the ROC curve to find the best cut-off point which minimizes the overall error (sum of error type I and error type II).

According to the results in Tables 15 and 17, we observe that the Logistics regression allows to have a satisfactory overall result in terms of correct classification rate $(97.83 \%$, $92.56 \%, 94.35 \%, 96.24 \%, 97.85 \%$ and $98.47 \%$ for the years 2008, 2009, 2010, 2011, 2012 and 2013). The Logit model permits to classify correctly 99.75\%,97.59\%, 97.60\%, $97.62 \%, 99.06 \%$ and $99.52 \%$ of the non-failed banks over the period 2008-2013. In this sense, the model misclassify only $0.33 \%, 2.41 \%, 2.4 \%, 2.38 \%, 0.94 \%$ and $0.48 \%$ of the non failed banks (error type II). In the other hand, we obtained a higher error rate type I $(62.16 \%, 48.85 \%, 38.15 \%, 20.55 \%, 33.33 \%$ and $60 \%)$ which means that the model was not able to classify correctly the bankrupt banks.

The research of the critical point by the ROC curve in the Logit model gives the following results (Table 16):

In 2008, the best critical point corresponds to the value of 0.0402 (cf. figures $1 \& 2$ ) the model of the logistic regression makes it possible to obtain a rate of good ranking of $92.36 \%$. Thus, $7.64 \%$ of the banks were not correctly classified. Indeed, 4 failing banks 
were assigned to the classes of the non-failed banks (error type I was 10.81\%). On the other hand, 91 healthy banks were predicted as failing (error type II was 7.54\%).

The results of year 2009 show a rate of bad classification of about $16.12 \%$ which means that $83.88 \%$ of the banks were correctly classified. The confusion matrix also shows that 12 failing banks were assigned to the group of healthy banks (error type I 9.16\%). However, 183 healthy banks were declared like failing banks (error type II $16.96 \%)$.

For the year 2010, the Logistic regression did not succeed in classifying $10.10 \%$ of the banks correctly. Indeed, 8 failing banks were assigned to the group of healthy banks (error type $\mathrm{I}=6.56 \%$ ) and 101 healthy banks were classified as failing banks (error type II $10.55 \%$ ). The Logit model made it possible to correctly classify $93.44 \%$ from failing banks and $89.45 \%$ of non-failed banks.

For the year 2011, 100\% of failing banks were correctly classified. According to the confusion matrix, we noticed that 70 active banks were assigned to the group of failing banks (error type II 7.92\%).

The same results are observed in 2012 and 2013 in terms of sensitivity (100\%)which means that the Logit model classify correctly all the failed banks (error type I 0\%)

As a conclusion, one can say that the results of the logistic regression are overall satisfactory in terms of \% of error type I. (0\% per 2011, 2012 and 2013 - \% of failed banks correctly predicted). We also validated that the error rate of the type $\mathrm{I}$ is larger with the discriminating analysis than with the Logit model over the whole period of analysis. Using the matrices of confusion, we could also check that the discriminating analysis does not manage to detect the banks which are really in bankruptcy. On the other hand, with the Logit model, the error of classification of the failing banks in the group of the active banks is not very high.

It is clear that for the years from 2011 to 2013, the Logit model classifies the whole of the failing banks correctly (sensitivity 100\%). The discriminating analysis makes it possible to have weaker error rates of the type II $(8.12 \% ; 7.60 \% ; 3.24 \% ; 2.71 \% ; 0.00 \%$ and $0.00 \%$ against $7.54 \% ; 16.96 \% ; 10.55 \% ; 7.92 \% ; 6.46 \%$ and $3.23 \%$ for the Logit model over the period 2008-2013). This shows the supremacy of the logistic regression in term of forecast of failure. For example, for the year 2009, among the 183 banks predicted like failing, 163 banks really will default in the following years.

Lastly, for better apprehending the impact of the choice of the cut-off on the classification and the forecast in the two models applied, we propose to compare results (average of values obtained on the totality of the period of 2008 to 2013 for the whole set of parameters of the obtained matrices of confusions (Table 18)).

For that purpose, we compared the results of the probability of default and the D-score derived from the score function with the following thresholds:

- The theoretical threshold $\left(\mathrm{P}^{*}=0.5\right.$; critical cut-off for the DA)

- The critical point obtained by the ROC curve

For the Logistic analysis, the results show the supremacy of the latter to generate better results in term of rate of good classification on average about $96.22 \%$ with a 
theoretical cut-off of 0.5 . However, by calculating the probability of default with the critical limit of the ROC curve, the Logistic regression makes it possible to reduce the error type I (4.42\% (ROC) against $42.67 \%$ (theoretical cut-off)). Furthermore, by using the theoretical score, the Logit model permits to classify on average $98.51 \%$ of the non-failed banks. On the other hand, by using the critical score of the ROC curve, we obtained success rates of classification of the non-failed banks on average $91.22 \%$. For type II error, which informs us about the predictive power of the model to detect defaulted banks, we demonstrate the supremacy of the Logit model using the optimal cut-off of the ROC curve (average error type II: 1,49\% (theoretical cut-off) against 8,78\% $(\mathrm{ROC})$ ).

The comparison of the overall results of the discriminant analysis show that the model using the optimal cut-off of the ROC curve abtain more accurate results in term of average correct classification (95.72\% against $93.36 \%$ (theoretical cut-off)).

We also observed that the Discriminant Analysis with a cut-off of the ROC curve reduce on average the error type I ( $24.74 \%$ vs $13.14 \%)$ and the error type II $(5.75 \%$ vs $3.61 \%)$.

For error type II, which informs us about the predictive power of the model to detect defaulted banks, and for error type I which provides information on the capacity of the model to recognize the failing banks, we demonstrate the supremacy of the Logit model using the optimal cut-off of the ROC curve.

\section{Conclusion}

This paper shows how accurately U.S bank failures can be predicted with Logit and Canonical Discriminant Analysis models by utilizing CAMEL's Variables.

First, Principal Component Analysis (PCA) was performed to compress the data dimension by keeping only the most important ratio combinations.

We compared different cut-off point formulas to provide and evaluate classification accordingly.

Our results confirm, first that the more accurate the theoretical critical probability of default value are, the more accurate the sensitivity of the model. In this sense comparative results over the entire period prove that correct classification was improved with the ROC curve cut-off value for both Logit and DA model. The first finding proves that sensitivity of classification is improved and in average Logit model outperforms DA (95.58\% vs $86.86 \%)$.

The second finding concerns the supremacy of ROC curve validation concerning the quality of the model by minimizing the error of misclassification of bankrupt banks: only $4.42 \%$ in average and $0 \%$ in both 2012 and 2013 .

Third, in term of correct classification (both for failed and non-failed banks) we prove that DA is better by using theoretical probability of default 0.5 (96.22\% against $93.36 \%$ ).

Finally, models were used to provide early warning signals. Moreover, The combination of the two models allows a better information about the future prospect of banks. Indeed, ROC curve validation emphasizes better prediction of bank failure because it 
delivers, in average, the highest error type II $8.78 \%$. This means that the model classifies some solvable banks in bankrupt group. So, we can conclude that the Logit was able to predict the failure of banks. Thus, it gives good signal about banks, which would failed one or two year later.

Overall, the study reveals also that our choice resulting from combinations of ten financial ratios which represent Capital adequacy, Assets quality, Earnings ability and Liquidity are obvious determinants of predicting bankruptcy.

Our results can be used for several purposes. For instance, regulators and banks can predict problems in order to avoid financial distress which can lead to bankruptcy. This improves banking supervision to establish supervisory guidelines. In fact, our methodological framework helps to construct an Early Warning System that can be used by supervisory authorities to detect banks that present significant and serious risks.

\section{References}

Adya, M. and Collopy, F. (1998). How e! ective are neural networks at forecasting and prediction? a review and evaluation. J. Forecasting, 17:481-495.

Altman, E. I. (1968). Financial ratios, discriminant analysis and the prediction of corporate bankruptcy. The journal of finance, 23(4):589-609.

Altman, E. I. (1984). A further empirical investigation of the bankruptcy cost question. The Journal of Finance, 39(4):1067-1089.

Altman, E. I. and Narayanan, P. (1997). An international survey of business failure classification models. Financial Markets, Institutions \& Instruments, 6(2):1-57.

Avery, R. B., Hanweck, G. A., et al. (1984). A dynamic analysis of bank failures. Technical report, Board of Governors of the Federal Reserve System (US).

Aziz, M. A. and Dar, H. A. (2004). Predicting corporate financial distress: Whither do we stand? Department of Economics, Loughborough University.

Balcaen, S. and Ooghe, H. (2006). 35 years of studies on business failure: an overview of the classic statistical methodologies and their related problems. The British Accounting Review, 38(1):63-93.

Balcaen, S., Ooghe, H., et al. (2004). Alternative methodologies in studies on business failure: do they produce better results than the classical statistical methods? Vlerick Leuven Gent Management School Working Papers Series, (16).

Barr, R. S., Siems, T. F., et al. (1994). Predicting bank failure using dea to quantify management quality. Technical report, Federal Reserve Bank of Dallas.

Barth, J. R., Brumbaugh, R. D., Sauerhaft, D., Wang, G. H., et al. (1985). Thrift institution failures: causes and policy issues. In Federal Reserve Bank of Chicago Proceedings, number 68. 
Beaver, W. H. (1966). Financial ratios as predictors of failure. Journal of accounting research, pages $71-111$.

Benston, G. J. (1985). An analysis of the causes of savings and loan association failures. Salomon Brothers Center for the Study of Financial Institutions, Graduate School of Business Administration, New York University.

Bilderbeek, J. (1979). Empirical-study of the predictive ability of financial ratios in the netherlands. Zeitschrift fur Betriebswirtschaft, 49(5):388-407.

Canbas, S., Cabuk, A., and Kilic, S. B. (2005). Prediction of commercial bank failure via multivariate statistical analysis of financial structures: The turkish case. European Journal of Operational Research, 166(2):528-546.

Coakley, J. R. and Brown, C. E. (2000). Artificial neural networks in accounting and finance: Modeling issues. International Journal of Intelligent Systems in Accounting, Finance \& Management, 9(2):119-144.

Dabos, M. and Sosa-Escudero, W. (2004). Explaining and predicting bank failure using duration models: The case of argentina after the mexican crisis. Revista de Análisis Económico, 19(1).

Dimitras, A. I., Zanakis, S. H., and Zopounidis, C. (1996). A survey of business failures with an emphasis on prediction methods and industrial applications. European Journal of Operational Research, 90(3):487-513.

Du Jardin, P. (2010). Predicting bankruptcy using neural networks and other classification methods: The influence of variable selection techniques on model accuracy. Neurocomputing, 73(10):2047-2060.

Frydman, H., Altman, E. I., and KAO, D.-L. (1985). Introducing recursive partitioning for financial classification: the case of financial distress. The Journal of Finance, 40(1):269-291.

Hair, J., Black, W., Babin, B., and Anderson, R. (2010). Multivariate data analysis: a global perspective, pearson. Upper Saddle River, NJ.

Hassan Al-Tamimi, H. A. and Charif, H. (2011). Multiple approaches in performance assessment of uae commercial banks. International Journal of Islamic and Middle Eastern Finance and Management, 4(1):74-82.

Jagtiani, J., Kolari, J., Lemieux, C., Shin, H., et al. (2003). Early warning models for bank supervision: Simpler could be better. ECONOMIC PERSPECTIVESFEDERAL RESERVE BANK OF CHICAGO, 27(3):49-59.

Jo, H., Han, I., and Lee, H. (1997). Bankruptcy prediction using case-based reasoning, neural networks, and discriminant analysis. Expert Systems with Applications, 13(2):97-108. 
Keasey, K. and Watson, R. (1991). Financial distress prediction models: A review of their usefulness1. British journal of Management, 2(2):89-102.

Kolari, J., Caputo, M., and Wagner, D. (1996). Trait recognition: An alternative approach to early warning systems in commercial banking. Journal of Business Finance E Accounting, 23(9-10):1415-1434.

Kolari, J., Glennon, D., Shin, H., and Caputo, M. (2002). Predicting large us commercial bank failures. Journal of Economics and Business, 54(4):361-387.

Kumar, P. R. and Ravi, V. (2007). Bankruptcy prediction in banks and firms via statistical and intelligent techniques-a review. European journal of operational research, 180(1):1-28.

Lanine, G. and Vander Vennet, R. (2006). Failure prediction in the russian bank sector with logit and trait recognition models. Expert Systems with Applications, 30(3):463478.

Lau, A. H.-L. (1987). A five-state financial distress prediction model. Journal of accounting research, pages 127-138.

Marais, M. L., Patell, J. M., and Wolfson, M. A. (1984). The experimental design of classification models: An application of recursive partitioning and bootstrapping to commercial bank loan classifications. Journal of accounting Research, pages 87-114.

Martin, D. (1977). Early warning of bank failure: A logit regression approach. Journal of banking \& finance, 1(3):249-276.

Messier Jr, W. F. and Hansen, J. V. (1988). Inducing rules for expert system development: an example using default and bankruptcy data. Management Science, 34(12):1403-1415.

Ohlson, J. A. (1980). Financial ratios and the probabilistic prediction of bankruptcy. Journal of accounting research, pages 109-131.

O'leary, D. E. (1998). Using neural networks to predict corporate failure. International Journal of Intelligent Systems in Accounting, Finance \& Management, 7(3):187-197.

Pantalone, C. C., Platt, M. B., et al. (1987). Predicting commercial bank failure since deregulation. New England Economic Review, (Jul):37-47.

Sinkey, J. F. (1975). A multivariate statistical analysis of the characteristics of problem banks. The Journal of Finance, 30(1):21-36.

Sinkey, J. F. (1978). Identifying" problem" banks: How do the banking authorities measure a bank's risk exposure? Journal of Money, Credit and Banking, 10(2):184193. 
Tennyson, B. M., Ingram, R. W., and Dugan, M. T. (1990). Assessing the information content of narrative disclosures in explaining bankruptcy. Journal of Business Finance Ef Accounting, 17(3):391-410.

Thomson, J. B. (1991). Predicting bank failures in the 1980s. Economic Review-Federal Reserve Bank of Cleveland, 27(1):9.

Tsai, C.-F. and Wu, J.-W. (2008). Using neural network ensembles for bankruptcy prediction and credit scoring. Expert Systems with Applications, 34(4):2639-2649.

Vellido, A., Lisboa, P. J., and Vaughan, J. (1999). Neural networks in business: a survey of applications (1992-1998). Expert systems with applications, 17(1):51-70.

Wong, B. K., Bodnovich, T. A., and Selvi, Y. (1997). Neural network applications in business: A review and analysis of the literature (1988-1995). Decision Support Systems, 19(4):301-320.

Zavgren, C. V. (1985). Assessing the vulnerability to failure of american industrial firms: a logistic analysis. Journal of Business Finance 8 Accounting, 12(1):19-45.

Zhang, G., Patuwo, B. E., and Hu, M. Y. (1998). Forecasting with artificial neural networks:: The state of the art. International journal of forecasting, 14(1):35-62.

Zopounidis, C. and Dimitras, A. (1993). The forecasting of business failure: Overview of methods and new avenues. Applied Stochastic Models and Data Analysis, World Scientific Publ., London.

\section{List of Tables}

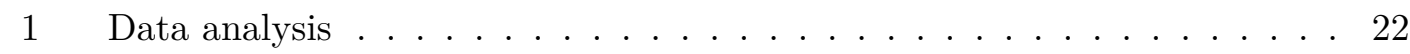

$2 \quad$ Means of the ten variables . . . . . . . . . . . . . . . . . . 23

3 Correlation coefficients between the explanatory variables and the dependent variable . . . . . . . . . . . . . . . . . . . 24

$4 \quad$ Correlation Matrix . . . . . . . . . . . . . . . . . . . . 25

5 Results of Bartlett's test of sphericity and KMO . . . . . . . . . . . . 26

6 Eigenvalues of the factors $\ldots \ldots \ldots \ldots \ldots \ldots$. . . . . . . . . . 27

7 Factors Loading . . . . . . . . . . . . . . . . . . . . . 28

$8 \quad$ Factor scores coefficient matrix . . . . . . . . . . . . . . . . . . . 29

$9 \quad$ Statistics of the estimated CDA model . . . . . . . . . . . . . . . . . . . . 29

10 Factor Structure Matrix - Correlations . . . . . . . . . . . . . . . . . . . 30

11 Significance tests of factors . . . . . . . . . . . . . . . . . 31

12 Statistical tests of Logit models . . . . . . . . . . . . . . . . . . . . . 32

13 Confusion Matrix . . . . . . . . . . . . . . . . . . . . . . . . . . 32

14 Results of DA confusion matrix . . . . . . . . . . . . . . . . . 33

15 Results of Logit . . . . . . . . . . . . . . . . . . . . . . . 33 
16 classification results with ROC curve . . . . . . . . . . . . . . . . . 34

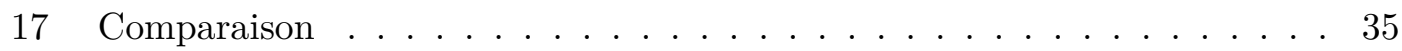

18 Average Results $\ldots \ldots \ldots \ldots \ldots$. . . . . . . . . . . . . . 36

\section{List of Figures}

$1 \quad$ ROC curve CDA vs Logit regression . . . . . . . . . . . . . . . . . 37

$2 \quad$ Best cut off point that maximizes the sensitivity and the specificity . . . . 39

$3 \quad$ Error type I and II : Logit vs CDA . . . . . . . . . . . . . . . . . 41

Table 1: Data analysis

\begin{tabular}{ccc}
\hline Year & Number of failed banks & Number of non-failed bank \\
\hline 2013 & 15 & 836 \\
2012 & 33 & 851 \\
2011 & 73 & 884 \\
2010 & 122 & 957 \\
2009 & 131 & 1079 \\
2008 & 37 & 1207 \\
\hline
\end{tabular}


Table 2: Means of the ten variables

\begin{tabular}{|c|c|c|c|c|c|c|c|}
\hline Variable & Years & NAB & $\mathrm{AB}$ & Variable & Years & NAB & $\mathrm{AB}$ \\
\hline \multirow[t]{6}{*}{ EQTA } & 2008 & $3.74 \%$ & $10.33 \%$ & \multirow[t]{6}{*}{ EQTL } & 2008 & $5.43 \%$ & $16.57 \%$ \\
\hline & 2009 & $1.48 \%$ & $9.72 \%$ & & 2009 & $2.27 \%$ & $16.07 \%$ \\
\hline & 2010 & $1.32 \%$ & $10.04 \%$ & & 2010 & $1.91 \%$ & $17.11 \%$ \\
\hline & 2011 & $1.04 \%$ & $10.76 \%$ & & 2011 & $1.60 \%$ & $18.94 \%$ \\
\hline & 2012 & $0.51 \%$ & $11.13 \%$ & & 2012 & $0.86 \%$ & $20.32 \%$ \\
\hline & 2013 & $1.13 \%$ & $11.34 \%$ & & 2013 & $1.87 \%$ & $19.83 \%$ \\
\hline Variable & Years & NAB & $\mathrm{AB}$ & Variable & Years & $\mathrm{NAB}$ & $\mathrm{AB}$ \\
\hline \multirow[t]{6}{*}{ NPLTA } & 2008 & $13.35 \%$ & $2.64 \%$ & \multirow[t]{6}{*}{ NPLGL } & 2008 & $17.75 \%$ & $3.58 \%$ \\
\hline & 2009 & $11.82 \%$ & $3.49 \%$ & & 2009 & $16.27 \%$ & $4.92 \%$ \\
\hline & 2010 & $12.95 \%$ & $3.12 \%$ & & 2010 & $17.83 \%$ & $4.57 \%$ \\
\hline & 2011 & $11.97 \%$ & $2.54 \%$ & & 2011 & $17.25 \%$ & $3.87 \%$ \\
\hline & 2012 & $10.23 \%$ & $1.94 \%$ & & 2012 & $16.38 \%$ & $3.04 \%$ \\
\hline & 2013 & $9.39 \%$ & $1.47 \%$ & & 2013 & $14.01 \%$ & $2.32 \%$ \\
\hline Variable & Years & NAB & $\mathrm{AB}$ & Variable & Years & NAB & $\mathrm{AB}$ \\
\hline \multirow[t]{6}{*}{ LLRTA } & 2008 & $3.27 \%$ & $1.23 \%$ & \multirow[t]{6}{*}{ LLRGL } & 2008 & $4.39 \%$ & $1.71 \%$ \\
\hline & 2009 & $3.43 \%$ & $1.47 \%$ & & 2009 & $4.73 \%$ & $2.11 \%$ \\
\hline & 2010 & $3.46 \%$ & $1.46 \%$ & & 2010 & $4.75 \%$ & $2.17 \%$ \\
\hline & 2011 & $3.59 \%$ & $1.32 \%$ & & 2011 & $5.17 \%$ & $2.02 \%$ \\
\hline & 2012 & $3.03 \%$ & $1.17 \%$ & & 2012 & $4.75 \%$ & $1.85 \%$ \\
\hline & 2013 & $2.96 \%$ & $1.06 \%$ & & 2013 & $4.39 \%$ & $1.68 \%$ \\
\hline Variable & Years & NAB & $\mathrm{AB}$ & Variable & Years & NAB & $\mathrm{AB}$ \\
\hline \multirow[t]{6}{*}{$\mathrm{ROA}$} & 2008 & $-5.53 \%$ & $-0.50 \%$ & \multirow[t]{6}{*}{$\mathrm{ROE}$} & 2008 & $-155.24 \%$ & $-9.42 \%$ \\
\hline & 2009 & $-6.27 \%$ & $-0.90 \%$ & & 2009 & $1266.86 \%$ & $15.53 \%$ \\
\hline & 2010 & $-3.51 \%$ & $-0.30 \%$ & & 2010 & $-306.91 \%$ & $-21.03 \%$ \\
\hline & 2011 & $-2.84 \%$ & $0.21 \%$ & & 2011 & $6.11 \%$ & $-5.23 \%$ \\
\hline & 2012 & $-2.90 \%$ & $0.60 \%$ & & 2012 & $-1016.60 \%$ & $4.68 \%$ \\
\hline & 2013 & $-1.91 \%$ & $0.70 \%$ & & 2013 & $-1076.54 \%$ & $7.01 \%$ \\
\hline Variable & Years & NAB & $\mathrm{AB}$ & Variable & Years & NAB & $\mathrm{AB}$ \\
\hline \multirow[t]{6}{*}{ TLTD } & 2008 & $83.08 \%$ & $91.13 \%$ & \multirow[t]{6}{*}{ TDTA } & 2008 & 0.8673 & $78.47 \%$ \\
\hline & 2009 & $75.80 \%$ & $82.63 \%$ & & 2009 & $91.17 \%$ & $80.93 \%$ \\
\hline & 2010 & $75.51 \%$ & $80.13 \%$ & & 2010 & $91.84 \%$ & $81.67 \%$ \\
\hline & 2011 & $70.94 \%$ & $77.79 \%$ & & 2011 & $92.73 \%$ & $81.43 \%$ \\
\hline & 2012 & $64.77 \%$ & $76.51 \%$ & & 2012 & $94.71 \%$ & $81.59 \%$ \\
\hline & 2013 & $66.43 \%$ & $77.73 \%$ & & 2013 & $94.65 \%$ & $81.43 \%$ \\
\hline
\end{tabular}


Table 3: Correlation coefficients between the explanatory variables and the dependent variable

\begin{tabular}{c|cccccc} 
Variables & $\mathbf{2 0 0 8}$ & $\mathbf{2 0 0 9}$ & $\mathbf{2 0 1 0}$ & $\mathbf{2 0 1 1}$ & $\mathbf{2 0 1 2}$ & $\mathbf{2 0 1 3}$ \\
\hline EQTA & $-0,2210^{*}$ & $-0,5056^{*}$ & $-0,5486^{*}$ & $-0,5260^{*}$ & $-0,4347^{*}$ & $-0,2795^{*}$ \\
EQTL & $-0,1058^{*}$ & $-0,2764^{*}$ & $-0,3043^{*}$ & $-0,2774^{*}$ & $-0,1712^{*}$ & $-0,1311^{*}$ \\
NPLTA & $0,4146^{*}$ & $0,4729^{*}$ & $0,5974^{*}$ & $0,5944^{*}$ & $0,5487^{*}$ & $0,4556^{*}$ \\
NPLGL & $0,4122^{*}$ & $0,4713^{*}$ & $0,5861^{*}$ & $0,5856^{*}$ & $0,5740^{*}$ & $0,4469^{*}$ \\
LLRTA & $0,3227^{*}$ & $0,4278^{*}$ & $0,4628^{*}$ & $0,5214^{*}$ & $0,4456^{*}$ & $0,3777^{*}$ \\
LLRGL & $0,3116^{*}$ & $0,4202^{*}$ & $0,4454^{*}$ & $0,5162^{*}$ & $0,4472^{*}$ & $0,3347^{*}$ \\
ROA & $-0,3339^{*}$ & $-0,4925^{*}$ & $-0,4020^{*}$ & $-0,4382^{*}$ & $-0,4872^{*}$ & $-0,3162^{*}$ \\
ROE & $-0,2811^{*}$ & 0,0420 & $-0,1586^{*}$ & 0,0087 & $-0,2885^{*}$ & $-0,2697$ \\
TLTD & $-0,0586^{* *}$ & $-0,1068^{*}$ & $-0,0587^{* *}$ & $-0,0822^{* *}$ & $-0,1042^{*}$ & $-0,0672^{* *}$ \\
TDTA & $0,1129^{*}$ & $0,2683^{*}$ & $0,2686^{*}$ & $0,2483^{*}$ & $0,2094^{*}$ & $0,1457^{*}$ \\
& & & & & &
\end{tabular}

${ }^{*}$ Significant at $1 \%,{ }^{* *}$ Significant at $5 \%,{ }^{* * *}$ Significant at $10 \%$ 
Table 4: Correlation Matrix

\begin{tabular}{|c|c|c|c|c|c|c|c|c|c|c|c|}
\hline \multirow{8}{*}{2008} & Variables & EQTA & EQTL & NPLTA & NPLGL & LLRTA & LLRGL & ROA & ROE & TLTD & TDTA \\
\hline & EQTL & 0,6373 & 1 & $-0,1906$ & $-0,1427$ & $-0,2028$ & $-0,0521$ & 0,0898 & 0,0837 & $-0,3372$ & $-0,1846$ \\
\hline & NPLTA & $-0,2858$ & $-0,1906$ & 1 & 0,9784 & 0,6925 & 0,6330 & $-0,5540$ & $-0,3109$ & $-0,0305$ & 0,1964 \\
\hline & NPLGL & $-0,2835$ & $-0,1427$ & 0,9784 & 1 & 0,6644 & 0,6526 & $-0,5578$ & $-0,3255$ & $-0,0983$ & 0,1748 \\
\hline & LLRGL & $-0,1933$ & $-0,0521$ & 0,6330 & 0,6526 & 0,9161 & 1 & $-0,5567$ & $-0,3000$ & $-0,0981$ & 0,1047 \\
\hline & ROA & 0,1594 & 0,0898 & $-0,5540$ & $-0,5578$ & $-0,6006$ & $-0,5567$ & 1 & 0,4447 & 0,0649 & $-0,1431$ \\
\hline & ROE & 0,1659 & 0,0837 & $-0,3109$ & $-0,3255$ & $-0,3037$ & $-0,3000$ & 0,4447 & 1 & 0,0720 & $-0,1013$ \\
\hline & TLTD & 0,0397 & $-0,3372$ & $-0,0305$ & $-0,0983$ & 0,0713 & $-0,0981$ & 0,0649 & 0,0720 & 1 & $-0,4065$ \\
\hline
\end{tabular}

\begin{tabular}{|c|c|c|c|c|c|c|c|c|c|c|c|}
\hline \multirow{8}{*}{2009} & Variables & EQTA & EQTL & NPLTA & NPLGL & LLRTA & LLRGL & ROA & ROE & TLTD & TDTA \\
\hline & EQTA & 1 & 0,6472 & $-0,5584$ & $-0,5505$ & $-0,5019$ & $-0,4653$ & 0,5951 & 0,0497 & 0,1005 & $-0,4105$ \\
\hline & NPLTA & $-0,5584$ & $-0,3528$ & 1 & 0,9795 & 0,6452 & 0,5984 & $-0,6503$ & $-0,1281$ & $-0,0430$ & 0,2840 \\
\hline & NPLGL & $-0,5505$ & $-0,3311$ & 0,9795 & 1 & 0,6096 & 0,5986 & $-0,6525$ & $-0,0908$ & $-0,1180$ & 0,2663 \\
\hline & LLRGL & $-0,4653$ & $-0,2631$ & 0,5984 & 0,5986 & 0,9643 & 1 & $-0,7099$ & $-0,0541$ & $-0,1353$ & 0,1945 \\
\hline & ROA) & 0,5951 & 0,3496 & $-0,6503$ & $-0,6525$ & $-0,7071$ & $-0,7099$ & 1 & 0,0511 & 0,1502 & $-0,3255$ \\
\hline & ROE & 0,0497 & 0,0274 & $-0,1281$ & $-0,0908$ & $-0,0790$ & $-0,0541$ & 0,0511 & 1 & $-0,0143$ & $-0,0366$ \\
\hline & TLTD & 0,1005 & $-0,2926$ & $-0,0430$ & $-0,1180$ & 0,0015 & $-0,1353$ & 0,1502 & $-0,0143$ & 1 & $-0,2911$ \\
\hline
\end{tabular}

\begin{tabular}{|c|c|c|c|c|c|c|c|c|c|c|c|}
\hline \multirow{11}{*}{2010} & Variables & EQTA & EQTL & NPLTA & NPLGL & LLRTA & LLRGL & ROA & ROE & TLTD & TDTA \\
\hline & EQTA & 1 & 0,6178 & $-0,5878$ & $-0,5850$ & $-0,5066$ & $-0,4792$ & 0,5649 & 0,1448 & 0,0956 & $-0,4045$ \\
\hline & EQTL & 0,6178 & 1 & $-0,3720$ & $-0,3512$ & $-0,3673$ & $-0,2883$ & 0,3288 & 0,0809 & $-0,2476$ & $-0,2489$ \\
\hline & NPLTA & $-0,5878$ & $-0,3720$ & 1 & 0,9801 & 0,6528 & 0,6161 & $-0,6309$ & $-0,1195$ & $-0,0016$ & 0,2629 \\
\hline & NPLGL & $-0,5850$ & $-0,3512$ & 0,9801 & 1 & 0,6190 & 0,6200 & $-0,6341$ & $-0,1278$ & $-0,0694$ & 0,2521 \\
\hline & LLRTA & $-0,5066$ & $-0,3673$ & 0,6528 & 0,6190 & 1 & 0,9618 & $-0,6362$ & $-0,1029$ & 0,1740 & 0,1809 \\
\hline & LLRGL & $-0,4792$ & $-0,2883$ & 0,6161 & 0,6200 & 0,9618 & 1 & $-0,6384$ & $-0,1062$ & 0,0203 & 0,1663 \\
\hline & ROA & 0,5649 & 0,3288 & $-0,6309$ & $-0,6341$ & $-0,6362$ & $-0,6384$ & 1 & 0,1964 & 0,1234 & $-0,2862$ \\
\hline & ROE & 0,1448 & 0,0809 & $-0,1195$ & $-0,1278$ & $-0,1029$ & $-0,1062$ & 0,1964 & 1 & 0,0121 & $-0,0343$ \\
\hline & TLTD & 0,0956 & $-0,2476$ & $-0,0016$ & $-0,0694$ & 0,1740 & 0,0203 & 0,1234 & 0,0121 & 1 & $-0,3190$ \\
\hline & TDTA & $-0,4045$ & $-0,2489$ & 0,2629 & 0,2521 & 0,1809 & 0,1663 & $-0,2862$ & $-0,0343$ & $-0,3190$ & 1 \\
\hline
\end{tabular}

\begin{tabular}{|c|c|c|c|c|c|c|c|c|c|c|c|}
\hline \multirow{11}{*}{2011} & Variables & EQTA & EQTL & NPLTA & NPLGL & LLRTA & LLRGL & ROA & ROE & TLTD & TDTA \\
\hline & EQTA & 1 & 0,6263 & $-0,5236$ & $-0,5037$ & $-0,4773$ & $-0,4396$ & 0,5324 & 0,0246 & 0,1257 & $-0,3987$ \\
\hline & EQTL & 0,6263 & 1 & $-0,3293$ & $-0,2830$ & $-0,3629$ & $-0,2773$ & 0,2924 & 0,0149 & $-0,3046$ & $-0,2261$ \\
\hline & NPLTA & $-0,5236$ & $-0,3293$ & 1 & 0,9774 & 0,6936 & 0,6604 & $-0,6104$ & $-0,0334$ & 0,0101 & 0,1618 \\
\hline & NPLGL & $-0,5037$ & $-0,2830$ & 0,9774 & 1 & 0,6558 & 0,6660 & $-0,6197$ & $-0,0569$ & $-0,0735$ & 0,1547 \\
\hline & LLRTA & $-0,4773$ & $-0,3629$ & 0,6936 & 0,6558 & 1 & 0,9545 & $-0,5868$ & 0,0184 & 0,1671 & 0,1273 \\
\hline & LLRGL & $-0,4396$ & $-0,2773$ & 0,6604 & 0,6660 & 0,9545 & 1 & $-0,5956$ & $-0,0220$ & $-0,0256$ & 0,1226 \\
\hline & ROA & 0,5324 & 0,2924 & $-0,6104$ & $-0,6197$ & $-0,5868$ & $-0,5956$ & 1 & 0,0795 & 0,1514 & $-0,2320$ \\
\hline & ROE & 0,0246 & 0,0149 & $-0,0334$ & $-0,0569$ & 0,0184 & $-0,0220$ & 0,0795 & 1 & 0,0411 & $-0,0002$ \\
\hline & TLTD & 0,1257 & $-0,3046$ & 0,0101 & $-0,0735$ & 0,1671 & $-0,0256$ & 0,1514 & 0,0411 & 1 & $-0,3200$ \\
\hline & TDTA & $-0,3987$ & $-0,2261$ & 0,1618 & 0,1547 & 0,1273 & 0,1226 & $-0,2320$ & $-0,0002$ & $-0,3200$ & 1 \\
\hline
\end{tabular}

\begin{tabular}{|c|c|c|c|c|c|c|c|c|c|c|c|}
\hline \multirow{11}{*}{2012} & Variables & EQTA & EQTL & NPLTA & NPLGL & LLRTA & LLRGL & ROA & ROE & TLTD & TDTA \\
\hline & EQTA & 1 & 0,4540 & $-0,3820$ & $-0,3588$ & $-0,3220$ & $-0,2156$ & 0,4467 & 0,1307 & 0,0802 & $-0,3505$ \\
\hline & EQTL & 0,4540 & 1 & $-0,2166$ & $-0,1608$ & $-0,2718$ & $-0,1071$ & 0,1589 & 0,0512 & $-0,3626$ & $-0,1386$ \\
\hline & NPLTA & $-0,3820$ & $-0,2166$ & 1 & 0,9713 & 0,5909 & 0,5393 & $-0,5006$ & $-0,2203$ & 0,0394 & 0,0867 \\
\hline & NPLGL & $-0,3588$ & $-0,1608$ & 0,9713 & 1 & 0,5562 & 0,5792 & $-0,5077$ & $-0,1991$ & $-0,0835$ & 0,0962 \\
\hline & LLRTA & $-0,3220$ & $-0,2718$ & 0,5909 & 0,5562 & 1 & 0,9025 & $-0,3145$ & $-0,0848$ & 0,2033 & 0,0635 \\
\hline & LLRGL & $-0,2156$ & $-0,1071$ & 0,5393 & 0,5792 & 0,9025 & 1 & $-0,3294$ & $-0,0701$ & $-0,1029$ & 0,0609 \\
\hline & ROA & 0,4467 & 0,1589 & $-0,5006$ & $-0,5077$ & $-0,3145$ & $-0,3294$ & 1 & 0,2335 & 0,2156 & $-0,2600$ \\
\hline & ROE & 0,1307 & 0,0512 & $-0,2203$ & $-0,1991$ & $-0,0848$ & $-0,0701$ & 0,2335 & 1 & 0,0156 & $-0,0790$ \\
\hline & TLTD & 0,0802 & $-0,3626$ & 0,0394 & $-0,0835$ & 0,2033 & $-0,1029$ & 0,2156 & 0,0156 & 1 & $-0,3036$ \\
\hline & TDTA & $-0,3505$ & $-0,1386$ & 0,0867 & 0,0962 & 0,0635 & 0,0609 & $-0,2600$ & $-0,0790$ & $-0,3036$ & 1 \\
\hline
\end{tabular}

\begin{tabular}{|c|c|c|c|c|c|c|c|c|c|c|c|}
\hline \multirow{11}{*}{2013} & Variables & EQTA & EQTL & NPLTA & NPLGL & LLRTA & LLRGL & ROA & ROE & TLTD & TDTA \\
\hline & EQTA & 1 & 0,5373 & $-0,1598$ & $-0,1294$ & $-0,1388$ & 0,0319 & 0,2990 & 0,0792 & 0,0785 & $-0,3017$ \\
\hline & EQTL & 0,5373 & 1 & $-0,1307$ & $-0,0227$ & $-0,2133$ & 0,0547 & 0,1075 & 0,0364 & $-0,3447$ & $-0,1530$ \\
\hline & NPLTA & $-0,1598$ & $-0,1307$ & 1 & 0,9687 & 0,5225 & 0,4388 & $-0,2611$ & $-0,0514$ & 0,0690 & 0,0109 \\
\hline & NPLGL & $-0,1294$ & $-0,0227$ & 0,9687 & 1 & 0,4837 & 0,4897 & $-0,2659$ & $-0,0553$ & $-0,0552$ & 0,0169 \\
\hline & LLRTA & $-0,1388$ & $-0,2133$ & 0,5225 & 0,4837 & 1 & 0,8613 & $-0,0847$ & $-0,1284$ & 0,2403 & 0,0090 \\
\hline & LLRGL & 0,0319 & 0,0547 & 0,4388 & 0,4897 & 0,8613 & 1 & $-0,1258$ & $-0,1292$ & $-0,1129$ & 0,0194 \\
\hline & ROA & 0,2990 & 0,1075 & $-0,2611$ & $-0,2659$ & $-0,0847$ & $-0,1258$ & 1 & 0,1254 & 0,2132 & $-0,1488$ \\
\hline & ROE & 0,0792 & 0,0364 & $-0,0514$ & $-0,0595$ & $-0,1284$ & $-0,1292$ & 0,1254 & 1 & 0,0264 & $-0,0422$ \\
\hline & TLTD & 0,0785 & $-0,3447$ & 0,0690 & $-0,0552$ & 0,2403 & $-0,1129$ & 0,2132 & 0,0264 & 1 & $-0,3224$ \\
\hline & TDTA & $-0,3017$ & $-0,1530$ & 0,0109 & 0,0169 & 0,0090 & 0,0194 & $-0,1488$ & $-0,0422$ & $-0,3224$ & 1 \\
\hline
\end{tabular}


Table 5: Results of Bartlett's test of sphericity and KMO

\begin{tabular}{c|c|c|c|c|c}
$\mathbf{2 0 0 8}$ & & $\mathbf{2 0 0 9}$ & & $\mathbf{2 0 1 0}$ & \\
\hline Bartlett's test & & Bartlett's test & & Bartlett's test & \\
\hline CHISQ & 10377,26 & CHISQ & 12095,3 & CHISQ & 10597,54 \\
d.f. & 45 & d.f. & 45 & d.f. & 45 \\
p-value & 0 & p-value & 0 & p-value & 0 \\
KMO & 0,6299962 & KMO & 0,6490987 & KMO & 0,6334672
\end{tabular}

\begin{tabular}{c|c|c|c|c|c}
$\mathbf{2 0 1 1}$ & & $\mathbf{2 0 1 2}$ & & $\mathbf{2 0 1 3}$ & \\
\hline Bartlett's test & & Bartlett's test & & Bartlett's test & \\
\hline CHISQ & 9277,847 & CHISQ & 7054,398 & CHISQ & 6082,105 \\
d.f. & 45 & d.f. & 45 & d.f. & 45 \\
p-value & 0 & p-value & 0 & p-value & 0 \\
KMO & 0,5907141 & KMO & 0,5393469 & KMO & 0,4434393
\end{tabular}


Table 6: Eigenvalues of the factors

\begin{tabular}{c|ccc|c|ccc}
\multicolumn{7}{c}{$\mathbf{2 0 0 8}$} & \multicolumn{2}{c}{$\mathbf{2 0 0 9}$} \\
\hline Factors & Eigenvalues & Variance\% & Cumulative\% & Factors & Eigenvalues & Variance\% & Cumulative\% \\
\hline F1 & 4,1545 & 41,5445 & 41,54 & $\mathbf{F 1}$ & 4,6813 & 46,8132 & 46,8132 \\
F2 & 1,6153 & 16,1530 & 57,70 & $\mathbf{F 2}$ & 1,3230 & 13,2304 & 60,0436 \\
F3 & 1,4230 & 14,2295 & 71,93 & $\mathbf{F 3}$ & 1,1560 & 11,5604 & 71,6041 \\
F4 & 0,8856 & 8,8557 & 80,78 & $\mathbf{F 4}$ & 1,0152 & 10,1520 & 81,7560 \\
F5 & 0,6227 & 6,2267 & 87,01 & $\mathbf{F 5}$ & 0,7237 & 7,2366 & 88,9926 \\
F6 & 0,5534 & 5,5344 & 92,54 & $\mathbf{F 6}$ & 0,5204 & 5,2039 & 94,1965 \\
F7 & 0,4367 & 4,3670 & 96,91 & $\mathbf{F 7}$ & 0,3178 & 3,1784 & 97,3749 \\
F8 & 0,2354 & 2,3542 & 99,27 & $\mathbf{F 8}$ & 0,2248 & 2,2481 & 99,6230 \\
F9 & 0,0607 & 0,6074 & 99,87 & $\mathbf{F 9}$ & 0,0303 & 0,3026 & 99,9256 \\
F10 & 0,0127 & 0,1273 & 100 & $\mathbf{F 1 0}$ & 0,0074 & 0,0744 & 100
\end{tabular}

\begin{tabular}{|c|c|c|c|c|c|c|c|}
\hline 2010 & \multicolumn{7}{|c|}{2011} \\
\hline Factors & Eigenvalues & Variance\% & Cumulative\% & Factors & Eigenvalues & Variance\% & Cumulative\% \\
\hline F1 & 4,6600 & 46,5998 & 46,5998 & F1 & 4,4960 & 44,9600 & 44,9600 \\
\hline F2 & 1,3906 & 13,9055 & 60,5053 & F2 & 1,4375 & 14,3750 & 59,3350 \\
\hline F3 & 1,0895 & 10,8955 & 71,4008 & F3 & 1,2317 & 12,3170 & 71,6520 \\
\hline F4 & 0,9841 & 9,8413 & 81,2421 & F4 & 1,0028 & 10,0285 & 81,6805 \\
\hline F5 & 0,6920 & 6,9195 & 88,1616 & F5 & 0,6253 & 6,2527 & 87,9332 \\
\hline F6 & 0,5175 & 5,1747 & 93,3363 & F6 & 0,5291 & 5,2910 & 93,2242 \\
\hline F7 & 0,3652 & 3,6521 & 96,9884 & F7 & 0,4074 & 4,0738 & 97,2980 \\
\hline F8 & 0,2623 & 2,6230 & 99,6115 & F8 & 0,2322 & 2,3218 & 99,6199 \\
\hline F9 & 0,0321 & 0,3207 & 99,9322 & F9 & 0,0303 & 0,3027 & 99,9226 \\
\hline F10 & 0,0068 & 0,0678 & 100 & F10 & 0,0077 & 0,0774 & 100 \\
\hline
\end{tabular}

\begin{tabular}{|c|c|c|c|c|c|c|c|}
\hline 2012 & & & & 2013 & & & \\
\hline Factors & Eigenvalues & Variance\% & Cumulative\% & Factors & Eigenvalues & Variance\% & Cumulative\% \\
\hline F1 & 3,7893 & 37,8931 & 37,8931 & F1 & 3,0532 & 30,5320 & 30,5320 \\
\hline F2 & 1,5727 & 15,7268 & 53,6200 & F2 & 1,7585 & 17,5846 & 48,1165 \\
\hline F3 & 1,3784 & 13,7844 & 67,4044 & F3 & 1,5399 & 15,3995 & 63,5160 \\
\hline F4 & 1,0208 & 10,2080 & 77,6124 & F4 & 1,0564 & 10,5643 & 74,0803 \\
\hline F5 & 0,7640 & 7,6401 & 85,2525 & F5 & 0,9499 & 9,4987 & 83,5790 \\
\hline F6 & 0,5656 & 5,6558 & 90,9083 & F6 & 0,7128 & 7,1283 & 90,7073 \\
\hline F7 & 0,4723 & 4,7225 & 95,6308 & F7 & 0,5387 & 5,3870 & 96,0943 \\
\hline F8 & 0,3821 & 3,8213 & 99,4521 & F8 & 0,3223 & 3,2235 & 99,3178 \\
\hline F9 & 0,0433 & 0,4327 & 99,8848 & F9 & 0,0548 & 0,5483 & 99,8661 \\
\hline F10 & 0,0115 & 0,1152 & 100 & F10 & 0,0134 & 0,1339 & 100 \\
\hline
\end{tabular}


Table 7: Factors Loading

\begin{tabular}{|c|c|c|c|c|c|c|c|c|}
\hline 2008 & & & & 2009 & & & & \\
\hline Variables & F1 & F2 & F3 & Variables & F1 & F2 & F3 & F4 \\
\hline EQTA & & 0,83633 & & EQTA & & & $-0,73457$ & \\
\hline EQTL & & 0,92147 & & EQTL & & & $-0,83003$ & \\
\hline NPLTA & $-0,86968$ & & & NPLTA & $-0,9166$ & & & \\
\hline NPLGL & $-0,87377$ & & & NPLGL & $-0,90976$ & & & \\
\hline LLRTA & $-0,88724$ & & & LLRTA & $-0,81544$ & & & \\
\hline LLRGL & $-0,87416$ & & & LLRGL & $-0,81241$ & & & \\
\hline ROA & 0,75857 & & & ROA & 0,79376 & & & \\
\hline ROE & & & & ROE & & & & $-0,98403$ \\
\hline TLTD & & & 0,87396 & TLTD & & $-0,91381$ & & \\
\hline TDTA & & & $-0,77505$ & TDTA & & 0,56919 & 0,64032 & \\
\hline
\end{tabular}

\begin{tabular}{c|c|c|c|c|c|c|c|c}
2010 & & & 2011 & & & \\
\hline Variables & F1 & F2 & F3 & Variables & F1 & F2 & F3 & F4 \\
\hline EQTA & 0,50475 & & $-0,69426$ & EQTA & & & $-0,74261$ & \\
EQTL & & & $-0,88276$ & EQTL & & & $-0,85977$ \\
NPLTA & $-0,83952$ & & & NPLTA & $-0,88879$ & & \\
NPLGL & $-0,83936$ & & & NPLGL & $-0,89173$ & & \\
LLRTA & $-0,88932$ & & & LLRTA & $-0,87795$ & & \\
LLRGL & $-0,90309$ & & & LLRGL & $-0,89148$ & & \\
ROA & 0,76912 & & & ROA & 0,72363 & & \\
ROE & & & & ROE & & & \\
TLTD & & 0,90043 & & TLTD & & 0,9146 & \\
TDTA & & $-0,63782$ & 0,51363 & TDTA & & $-0,61087$ & 0,58144 &
\end{tabular}

\begin{tabular}{|c|c|c|c|c|c|c|c|c|c|}
\hline 2012 & & & & & 2013 & & & & \\
\hline Variables & F1 & F2 & F3 & F4 & Variables & F1 & F2 & F3 & F4 \\
\hline EQTA & & 0,72974 & & & EQTA & & 0,76275 & & \\
\hline EQTL & & & 0,80884 & & EQTL & & 0,90457 & & \\
\hline NPLGL & $-0,8227$ & & & & NPLGL & 0,94447 & & & \\
\hline LLRTA & $-0,88558$ & & & & LLRTA & 0,63648 & & & $-0,62689$ \\
\hline LLRGL & $-0,90438$ & & & & LLRGL & 0,61686 & & & $-0,65394$ \\
\hline ROE & & & & 0,8728 & ROE & & & & 0,69764 \\
\hline TLTD & & & $-0,81233$ & & TLTD & & & 0,80717 & \\
\hline TDTA & & $-0,80568$ & & & TDTA & & & $-0,65367$ & \\
\hline
\end{tabular}


Table 8: Factor scores coefficient matrix

\begin{tabular}{|c|c|c|c|c|c|c|c|c|c|c|c|}
\hline 2008 & Variables & EQTA & EQTL & NPLTA & NPLGL & LLRTA & LLRGL & ROA & ROE & TLTD & TDTA \\
\hline & F1 & $-0,0869$ & $-0,1276$ & $-0,4344$ & $-0,4411$ & $-0,4699$ & $-0,4796$ & 0,4039 & 0,2331 & $-0,0227$ & 0,0961 \\
\hline & F2 & 0,6399 & 0,7241 & $-0,0240$ & 0,0119 & 0,0136 & 0,1262 & $-0,0851$ & $-0,0104$ & $-0,2164$ & $-0,2480$ \\
\hline & F3 & 0,1490 & $-0,1450$ & 0,0110 & $-0,0210$ & 0,1361 & 0,0505 & 0,0035 & 0,0706 & 0,7317 & $-0,6433$ \\
\hline \multirow[t]{5}{*}{2009} & Variables & EQTA & EQTL & NPLTA & NPLGL & LLRTA & LLRGL & ROA & ROE & TLTD & TDTA \\
\hline & F1 & 0,0526 & 0,2239 & 0,4204 & 0,4235 & 0,5799 & 0,6164 & $-0,3893$ & $-0,0163$ & $-0,0040$ & $-0,3311$ \\
\hline & F2 & $-0,0430$ & 0,3255 & $-0,0292$ & 0,0187 & $-0,1126$ & $-0,0210$ & $-0,0751$ & $-0,0139$ & $-0,8006$ & 0,4998 \\
\hline & F3 & $-0,5576$ & $-0,7362$ & $-0,0173$ & $-0,0399$ & $-0,1957$ & $-0,2846$ & $-0,0061$ & $-0,0402$ & 0,1278 & 0,6121 \\
\hline & F4 & 0,0101 & 0,0272 & 0,1389 & 0,1435 & $-0,1050$ & $-0,1077$ & 0,0501 & 0,9680 & 0,0074 & $-0,0233$ \\
\hline \multirow[t]{4}{*}{2010} & Variables & EQTA & EQTL & NPLTA & NPLGL & LLRTA & LLRGL & ROA & ROE & TLTD & TDTA \\
\hline & F1 & $-0,0363$ & $-0,3190$ & $-0,4363$ & $-0,4489$ & $-0,5479$ & $-0,6048$ & 0,4048 & 0,0705 & 0,0652 & 0,2344 \\
\hline & F2 & 0,1129 & $-0,2369$ & $-0,0300$ & $-0,0746$ & 0,2042 & 0,1056 & 0,1272 & 0,0386 & 0,7782 & $-0,5135$ \\
\hline & F3 & $-0,5282$ & $-0,8556$ & $-0,0326$ & $-0,0658$ & $-0,1490$ & $-0,2640$ & 0,0599 & $-0,0225$ & 0,2636 & 0,4544 \\
\hline \multirow[t]{5}{*}{2011} & Variables & EQTA & EQTL & NPLTA & NPLGL & LLRTA & LLRGL & ROA & ROE & TLTD & TDTA \\
\hline & F1 & $-0,0386$ & $-0,2362$ & $-0,4921$ & $-0,5125$ & $-0,4902$ & $-0,5353$ & 0,3481 & $-0,0307$ & 0,0579 & 0,2420 \\
\hline & F2 & 0,1132 & $-0,3093$ & 0,0069 & $-0,0516$ & 0,1679 & 0,0415 & 0,1566 & $-0,0311$ & 0,7752 & $-0,4906$ \\
\hline & F3 & $-0,5623$ & $-0,7718$ & $-0,0942$ & $-0,1448$ & $-0,0720$ & $-0,1745$ & $-0,0108$ & $-0,0071$ & 0,1923 & 0,5092 \\
\hline & F4 & 0,0079 & 0,0322 & $-0,0130$ & $-0,0369$ & 0,0882 & 0,0537 & 0,0718 & 0,9895 & 0,0064 & 0,0766 \\
\hline \multirow[t]{5}{*}{2012} & Variables & EQTA & EQTL & NPLTA & NPLGL & LLRTA & LLRGL & ROA & ROE & TLTD & TDTA \\
\hline & F1 & $-0,0692$ & $-0,1301$ & $-0,4080$ & $-0,4339$ & $-0,5819$ & $-0,6438$ & 0,0927 & $-0,2015$ & 0,0170 & 0,1703 \\
\hline & F2 & 0,5575 & 0,3159 & 0,0823 & 0,0662 & 0,0878 & 0,0884 & 0,2851 & $-0,1409$ & 0,3444 & $-0,7001$ \\
\hline & F3 & 0,2440 & 0,6684 & $-0,0024$ & 0,0942 & $-0,1177$ & 0,1364 & $-0,1147$ & 0,0254 & $-0,6739$ & 0,1056 \\
\hline & F4 & $-0,0065$ & $-0,0531$ & $-0,2383$ & $-0,2075$ & 0,2627 & 0,2978 & 0,2558 & 0,8788 & $-0,0708$ & 0,1678 \\
\hline \multirow[t]{5}{*}{2013} & Variables & EQTA & EQTL & NPLTA & NPLGL & LLRTA & LLRGL & ROA & ROE & TLTD & TDTA \\
\hline & F1 & 0,0159 & 0,0627 & 0,6599 & 0,6654 & 0,2252 & 0,2222 & $-0,1987$ & 0,3370 & 0,0179 & $-0,1515$ \\
\hline & F2 & 0,5612 & 0,7038 & $-0,0295$ & 0,0651 & $-0,0760$ & 0,1973 & 0,1104 & 0,0247 & $-0,3548$ & $-0,1556$ \\
\hline & F3 & 0,2636 & $-0,1420$ & $-0,0001$ & $-0,0705$ & 0,2065 & 0,0173 & 0,4148 & 0,1139 & 0,6595 & $-0,5012$ \\
\hline & F4 & $-0,0322$ & 0,0140 & 0,2538 & 0,2403 & $-0,4624$ & $-0,5034$ & $-0,1230$ & 0,7183 & 0,0195 & $-0,1575$ \\
\hline
\end{tabular}

Table 9: Statistics of the estimated CDA model

\begin{tabular}{c|cccccc} 
& 2008 & 2009 & 2010 & 2011 & 2012 & 2013 \\
\hline Eigenvalue & 0,2389 & 0,4626 & 0,6091 & 0,71 & 0,8013 & 0,4775 \\
Proportion & 1 & 1 & 1 & 1 & 1 & 1 \\
Canonical R & 0,4391 & 0,5624 & 0,6152 & 0,6444 & 0,667 & 0,5685 \\
Wilks Lambda & 0,8072 & 0,6837 & 0,6215 & 0,5848 & 0,5551 & 0,6768 \\
CHI-2 & 265,7519 & 458,5101 & 511,6064 & 511,2647 & 517,9045 & 330,6099 \\
d.f. & 3 & 4 & 3 & 4 & 4 & 4 \\
p-value & 0 & 0 & 0 & 0 & 0 & 0 \\
Sq Canonical corr. & 0,1928 & 0,3163 & 0,3785 & 0,4152 & 0,4449 & 0,3232
\end{tabular}


Table 10: Factor Structure Matrix - Correlations

\begin{tabular}{c|c|cccc} 
& & $\mathbf{F 1}$ & $\mathbf{F 2}$ & $\mathbf{F 3}$ & $\mathbf{F 4}$ \\
\hline $\mathbf{2 0 0 8}$ & Total & 0,9425 & 0,2781 & 0,1856 & \\
& Within & 0,9301 & 0,2517 & 0,1673 & \\
\hline $\mathbf{2 0 0 9}$ & Total & 0,8211 & $-0,1974$ & $-0,5231$ & $-0,0521$ \\
& Within & 0,7654 & $-0,1643$ & $-0,4525$ & $-0,0431$ \\
\hline $\mathbf{2 0 1 0}$ & Total & 0,854 & 0,2061 & $-0,4777$ & \\
& Within & 0,7913 & 0,1638 & $-0,3939$ & \\
\hline $\mathbf{2 0 1 1}$ & Total & 0,8903 & 0,1887 & $-0,4123$ & $-0,0416$ \\
& Within & 0,8312 & 0,1454 & $-0,3271$ & $-0,0318$ \\
\hline $\mathbf{2 0 1 2}$ & Total & 0,7712 & 0,4636 & 0,0223 & 0,4357 \\
& Within & 0,67 & 0,3632 & 0,0166 & 0,3393 \\
\hline $\mathbf{2 0 1 3}$ & Total & $-0,7434$ & 0,3153 & 0,3875 & 0,4447 \\
& Within & $-0,6749$ & 0,2637 & 0,3268 & 0,3781 \\
\hline
\end{tabular}


Table 11: Significance tests of factors

\begin{tabular}{|c|c|c|c|c|c|}
\hline 2008 & Attribute & Coef. & Std-dev & Wald & Signif \\
\hline & constant & $-6,5238^{*}$ & 0,5864 & 123,7532 & 0 \\
\hline & F1 & $-0,6245^{*}$ & 0,0764 & 66,7775 & 0 \\
\hline & $\mathrm{F} 2$ & $-3,0669^{*}$ & 0,4689 & 42,7782 & 0 \\
\hline & F3 & $-0,2908$ & 0,1599 & 3,3061 & 0,069 \\
\hline \multirow[t]{6}{*}{2009} & Attribute & Coef. & Std-dev & Wald & Signif \\
\hline & constant & $-4,0591^{*}$ & 0,2657 & 233,4688 & 0 \\
\hline & $\mathrm{F} 1$ & $-0,6651^{*}$ & 0,0636 & 109,4318 & 0 \\
\hline & $\mathrm{F} 2$ & $-0,1361$ & 0,1798 & 0,5729 & 0,4491 \\
\hline & F3 & $2,1396^{*}$ & 0,2257 & 89,8791 & 0 \\
\hline & F4 & 0,0076 & 0,2265 & 0,0011 & 0,9732 \\
\hline \multirow[t]{5}{*}{2010} & Attribute & Coef. & Std-dev & Wald & Signif \\
\hline & constant & $-4,9435^{*}$ & 0,3825 & 167,0195 & 0 \\
\hline & $\mathrm{F} 1$ & $-0,8357^{*}$ & 0,0773 & 117,0012 & 0 \\
\hline & $\mathrm{F} 2$ & $-0,0998$ & 0,0815 & 1,4984 & 0,2209 \\
\hline & F3 & $2,7505^{*}$ & 0,2744 & 100,4928 & 0 \\
\hline \multirow[t]{6}{*}{2011} & Attribute & Coef. & Std-dev & Wald & Signif \\
\hline & Constant & $-7,7326^{*}$ & 0,9651 & 64,1892 & 0 \\
\hline & F1 & $-1,1374^{*}$ & 0,1498 & 57,622 & 0 \\
\hline & $\mathrm{F} 2$ & 0,3166 & 0,1637 & 3,7415 & 0,0531 \\
\hline & F3 & $3,6381 *$ & 0,5187 & 49,1882 & 0 \\
\hline & $\mathrm{F} 4$ & 0,0173 & 0,1452 & 0,0143 & 0,9049 \\
\hline \multirow[t]{6}{*}{2012} & Attribute & Coef. & Std-dev & Wald & Signif \\
\hline & constant & $-7,5883^{*}$ & 1,1153 & 46,2949 & 0 \\
\hline & F1 & $-0,7508^{*}$ & 0,1334 & 31,6892 & 0 \\
\hline & $\mathrm{F} 2$ & $-2,1392^{*}$ & 0,4461 & 22,9925 & 0 \\
\hline & F3 & $-1,4157^{* *}$ & 0,6393 & 4,9046 & 0,0268 \\
\hline & $\mathrm{F} 4$ & $-0,6151^{*}$ & 0,2013 & 9,3375 & 0,0022 \\
\hline \multirow[t]{6}{*}{2013} & Attribute & Coef. & Std-dev & Wald & Signif \\
\hline & constant & $-8,2816^{*}$ & 1,3358 & 38,4348 & 0 \\
\hline & $\mathrm{F} 1$ & $0,4643^{*}$ & 0,1192 & 15,18 & 0,0001 \\
\hline & $\mathrm{F} 2$ & $-3,1646^{*}$ & 0,7601 & 17,3321 & 0 \\
\hline & F3 & $-0,3756^{* *}$ & 0,1696 & 4,9044 & 0,0268 \\
\hline & $\mathrm{F} 4$ & $-0,2193$ & 0,1621 & 1,831 & 0,176 \\
\hline
\end{tabular}

*Significant at $1 \%, * *$ Significant at $5 \%$ 
Table 12: Statistical tests of Logit models

\begin{tabular}{c|cccccc} 
Model & $\mathbf{2 0 0 8}$ & $\mathbf{2 0 0 9}$ & $\mathbf{2 0 1 0}$ & $\mathbf{2 0 1 1}$ & $\mathbf{2 0 1 2}$ & $\mathbf{2 0 1 3}$ \\
\hline Chi-2 test & 168,9029 & 390,3093 & 441,7951 & 359,6493 & 208,2682 & 107,2245 \\
d.f. & 3 & 4 & 3 & 4 & 4 & 4 \\
P(>Chi-2) & 0 & 0 & 0 & 0 & 0 & 0 \\
McFadden's R & 0,5072 & 0,4704 & 0,5802 & 0,697 & 0,7392 & 0,7106
\end{tabular}

Table 13: Confusion Matrix

\begin{tabular}{cccc} 
& \multicolumn{2}{c}{ PREDICTED class } \\
\hline & Bankruptcy $\mathrm{Y}=1$ & Bankruptcy Y=1 & Non Bankruptcy $\mathrm{Y}=0$ \\
\hline Actual class & correctly classified & bankrupt banks \\
incorrectly classified \\
(error type I) \\
Non Bankruptcy $\mathrm{Y}=0$ & $\begin{array}{c}\text { non-bankrupted banks } \\
\text { classifien-bankrupt banks } \\
\text { correctly classified } \\
\text { (error type II) }\end{array}$ &
\end{tabular}


Table 14: Results of DA confusion matrix

\begin{tabular}{c|c|c|c|c}
2008 & & Bankrupt & Non-bankrupt & Sum \\
\hline & Bankrupt & 27 & 10 & 37 \\
& Non-bankrupt & 79 & 1128 & 1207 \\
& Sum & 106 & 1138 & 1244 \\
\hline 2009 & & Bankrupt & Non-bankrupt & Sum \\
\hline & Bankrupt & 100 & 31 & 131 \\
& Non-bankrupt & 122 & 957 & 1079 \\
& Sum & 222 & 988 & 1210 \\
\hline 2010 & & Bankrupt & Non-bankrupt & Sum \\
\hline & Bankrupt & 102 & 20 & 122 \\
& Nonbankrupt & 88 & 869 & 957 \\
& Sum & 190 & 889 & 1079 \\
\hline 2011 & & Bankrupt & Non-bankrupt & Sum \\
\hline \multirow{4}{*}{} & Bankrupt & 60 & 13 & 73 \\
& Non-bankrupt & 49 & 835 & 884 \\
& Sum & 109 & 848 & 957 \\
\hline 2012 & & Bankrupt & Non-bankrupt & Sum \\
\hline & Bankrupt & 23 & 10 & 33 \\
& Non-bankrupt & 11 & 840 & 851 \\
& Sum & 34 & 850 & 884 \\
\hline 2013 & & Bankrupt & Non-bankrupt & Sum \\
\hline & Bankrupt & 10 & 5 & 15 \\
& Non-bankrupt & 5 & 831 & 836 \\
& Sum & 15 & 836 & 851 \\
& & & &
\end{tabular}

Table 15: Results of Logit

\begin{tabular}{c|cccccc} 
Logit model & $\mathbf{2 0 0 8}$ & $\mathbf{2 0 0 9}$ & $\mathbf{2 0 1 0}$ & $\mathbf{2 0 1 1}$ & $\mathbf{2 0 1 2}$ & $\mathbf{2 0 1 3}$ \\
\hline Failed banks correctly predicted & 14 & 67 & 84 & 58 & 22 & 6 \\
Non-failed banks correctly predicted & 1203 & 1053 & 934 & 863 & 843 & 832 \\
Error type I & 23 & 64 & 38 & 15 & 11 & 9 \\
Error type II & 4 & 26 & 23 & 21 & 8 & 4 \\
Incorrectly predicted total & 27 & 90 & 61 & 36 & 19 & 13 \\
Correctly predicted total & 1217 & 1120 & 1018 & 921 & 865 & 838 \\
\% of failed banks correctly predicted & $37,84 \%$ & $51,15 \%$ & $68,85 \%$ & $79,45 \%$ & $66,67 \%$ & $40,00 \%$ \\
\% of non-failed banks correctly predicted & $99,67 \%$ & $97,59 \%$ & $97,60 \%$ & $97,62 \%$ & $99,06 \%$ & $99,52 \%$ \\
\% of total incorrectly predicted & $2,17 \%$ & $7,44 \%$ & $5,65 \%$ & $3,76 \%$ & $2,15 \%$ & $1,53 \%$ \\
\% of total correctly predicted & $97,83 \%$ & $92,56 \%$ & $94,35 \%$ & $96,24 \%$ & $97,85 \%$ & $98,47 \%$
\end{tabular}


Table 16: classification results with ROC curve

\begin{tabular}{|c|c|c|c|c|c|c|}
\hline Logit model ROC curve & 2008 & 2009 & 2010 & 2011 & 2012 & 2013 \\
\hline Failed banks correctly predicted & 33 & 119 & 114 & 73 & 33 & 15 \\
\hline Non-failed banks correctly predicted & 1116 & 896 & 856 & 814 & 796 & 809 \\
\hline Error type I & 4 & 12 & 8 & 0 & 0 & 0 \\
\hline Error type II & 91 & 183 & 101 & 70 & 55 & 27 \\
\hline Incorrectly predicted total & 95 & 195 & 109 & 70 & 55 & 27 \\
\hline Correctly predicted total & 1149 & 1015 & 970 & 887 & 829 & 824 \\
\hline$\%$ of failed banks correctly predicted & $89,19 \%$ & $90,84 \%$ & $93,44 \%$ & $100,00 \%$ & $100,00 \%$ & $100,00 \%$ \\
\hline$\%$ of error type I & $10,81 \%$ & $9,16 \%$ & $6,56 \%$ & $0,00 \%$ & $0,00 \%$ & $0,00 \%$ \\
\hline$\%$ of non-failed banks correctly predicted & $92,46 \%$ & $83,04 \%$ & $89,45 \%$ & $92,08 \%$ & $93,54 \%$ & $96,77 \%$ \\
\hline$\%$ of error type II & $7,54 \%$ & $16,96 \%$ & $10,55 \%$ & $7,92 \%$ & $6,46 \%$ & $3,23 \%$ \\
\hline$\%$ of total incorrectly predicted & $7,64 \%$ & $16,12 \%$ & $10,10 \%$ & $7,31 \%$ & $6,22 \%$ & $3,17 \%$ \\
\hline$\%$ of total correctly predicted & $92,36 \%$ & $83,88 \%$ & $89,90 \%$ & $92,69 \%$ & $93,78 \%$ & $96,83 \%$ \\
\hline Canonical Discriminant Analysis & 2008 & 2009 & 2010 & 2011 & 2012 & 2013 \\
\hline Failed banks correctly predicted & 32 & 102 & 103 & 67 & 31 & 13 \\
\hline Non-failed banks correctly predicted & 1109 & 997 & 926 & 860 & 851 & 836 \\
\hline Error type I & 5 & 29 & 19 & 6 & 2 & 2 \\
\hline Error type II & 98 & 82 & 31 & 24 & 0 & 0 \\
\hline Incorrectly predicted total & 103 & 111 & 50 & 30 & 2 & 2 \\
\hline Correctly predicted total & 1141 & 1099 & 1029 & 927 & 882 & 849 \\
\hline$\%$ of failed banks correctly predicted & $86,49 \%$ & $77,86 \%$ & $84,43 \%$ & $91,78 \%$ & $93,94 \%$ & $86,67 \%$ \\
\hline$\%$ of error type I & $13,51 \%$ & $22,14 \%$ & $15,57 \%$ & $8,22 \%$ & $6,06 \%$ & $13,33 \%$ \\
\hline$\%$ of non-failed banks correctly predicted & $91,88 \%$ & $92,40 \%$ & $96,76 \%$ & $97,29 \%$ & $100,00 \%$ & $100,00 \%$ \\
\hline$\%$ of error type II & $8,12 \%$ & $7,60 \%$ & $3,24 \%$ & $2,71 \%$ & $0,00 \%$ & $0,00 \%$ \\
\hline$\%$ of total incorrectly predicted & $8,28 \%$ & $9,17 \%$ & $4,63 \%$ & $3,13 \%$ & $0,23 \%$ & $0,24 \%$ \\
\hline$\%$ of total correctly predicted & $91,72 \%$ & $90,83 \%$ & $95,37 \%$ & $96,87 \%$ & $99,77 \%$ & $99,76 \%$ \\
\hline
\end{tabular}


Table 17: Comparaison

\begin{tabular}{c|cc|cc|cc} 
Logit model & $\mathbf{2 0 0 8}$ & & $\mathbf{2 0 0 9}$ & $\mathbf{2 0 1 0}$ & \\
\hline & cut-off & ROC & cut-off & ROC & cut-off & ROC \\
\hline & 0,5 & 0,0402 & 0,5 & 0,0818 & 0,5 & 0,1139 \\
\hline Sensitivity & $37,84 \%$ & $89,19 \%$ & $51,15 \%$ & $90,84 \%$ & $68,85 \%$ & $93,44 \%$ \\
Error type I & $62,16 \%$ & $10,81 \%$ & $48,85 \%$ & $9,16 \%$ & $31,15 \%$ & $6,56 \%$ \\
Specificity & $99,67 \%$ & $92,46 \%$ & $97,59 \%$ & $83,04 \%$ & $97,60 \%$ & $89,45 \%$ \\
Error type II & $0,33 \%$ & $7,54 \%$ & $2,41 \%$ & $16,96 \%$ & $2,40 \%$ & $10,55 \%$ \\
Error rate & $2,17 \%$ & $7,64 \%$ & $7,44 \%$ & $16,12 \%$ & $5,65 \%$ & $10,10 \%$ \\
Correct classification & $97,83 \%$ & $92,36 \%$ & $92,56 \%$ & $83,88 \%$ & $94,35 \%$ & $89,90 \%$
\end{tabular}

\begin{tabular}{c|cc|cc|cc} 
Logit model & $\mathbf{2 0 1 1}$ & & $\mathbf{2 0 1 2}$ & & $\mathbf{2 0 1 3}$ & \\
\hline & cut-off & ROC & cut-off & ROC & cut-off & ROC \\
\hline & 0,5 & 0,0314 & 0,5 & 0,0077 & 0,5 & 0,0272 \\
\hline Sensitivity & $79,45 \%$ & $100,00 \%$ & $66,67 \%$ & $100,00 \%$ & $40,00 \%$ & $100,00 \%$ \\
Error type I & $20,55 \%$ & $0,00 \%$ & $33,33 \%$ & $0,00 \%$ & $60,00 \%$ & $0,00 \%$ \\
Specificity & $97,62 \%$ & $92,08 \%$ & $99,06 \%$ & $93,54 \%$ & $99,52 \%$ & $96,77 \%$ \\
Error type II & $2,38 \%$ & $7,92 \%$ & $0,94 \%$ & $6,46 \%$ & $0,48 \%$ & $3,23 \%$ \\
Error rate & $3,76 \%$ & $7,31 \%$ & $2,15 \%$ & $6,22 \%$ & $1,53 \%$ & $3,17 \%$ \\
Correct classification & $96,24 \%$ & $92,69 \%$ & $97,85 \%$ & $93,78 \%$ & $98,47 \%$ & $96,83 \%$
\end{tabular}

\begin{tabular}{c|cc|cc|cc} 
Canonical DA & \multicolumn{2}{|c}{$\mathbf{2 0 0 8}$} & \multicolumn{2}{c}{$\mathbf{2 0 0 9}$} & \multicolumn{2}{c}{$\mathbf{2 0 1 0}$} \\
\hline & cut-off & ROC & cut-off & ROC & cut-off & ROC \\
\hline & $-2,7039$ & $-1,4306$ & $-1,7135$ & $-0,3301$ & $-1,9055$ & $-0,779$ \\
\hline Sensitivity & $72,97 \%$ & $86,49 \%$ & $76,34 \%$ & $77,86 \%$ & $83,61 \%$ & $84,43 \%$ \\
Error type I & $27,03 \%$ & $13,51 \%$ & $23,66 \%$ & $22,14 \%$ & $16,39 \%$ & $15,57 \%$ \\
Specificity & $93,45 \%$ & $91,88 \%$ & $88,69 \%$ & $92,40 \%$ & $90,80 \%$ & $96,76 \%$ \\
Error type II & $6,55 \%$ & $8,12 \%$ & $11,31 \%$ & $7,60 \%$ & $9,20 \%$ & $3,24 \%$ \\
Error rate & $7,15 \%$ & $8,28 \%$ & $12,64 \%$ & $9,17 \%$ & $10,01 \%$ & $4,63 \%$ \\
Correct classification & $92,85 \%$ & $91,72 \%$ & $87,36 \%$ & $90,83 \%$ & $89,99 \%$ & $95,37 \%$
\end{tabular}

\begin{tabular}{c|cc|cc|cc} 
Canonical DA & \multicolumn{2}{|c}{$\mathbf{2 0 1 1}$} & \multicolumn{2}{c}{$\mathbf{2 0 1 2}$} & \multicolumn{2}{c}{$\mathbf{2 0 1 3}$} \\
\hline & cut-off & ROC & cut-off & ROC & cut-off & ROC \\
\hline & $-2,6872$ & $-1,8846$ & $-4,3646$ & $-1,8593$ & $-5,0601$ & $-0,9216$ \\
\hline Sensitivity & $82,19 \%$ & $91,78 \%$ & $69,70 \%$ & $93,94 \%$ & $66,67 \%$ & $86,67 \%$ \\
Error type I & $17,81 \%$ & $8,22 \%$ & $30,30 \%$ & $6,06 \%$ & $33,33 \%$ & $13,33 \%$ \\
Specificity & $94,46 \%$ & $97,29 \%$ & $98,71 \%$ & $100,00 \%$ & $99,40 \%$ & $100,00 \%$ \\
Error type II & $5,54 \%$ & $2,71 \%$ & $1,29 \%$ & $0,00 \%$ & $0,60 \%$ & $0,00 \%$ \\
Error rate & $6,48 \%$ & $3,13 \%$ & $2,38 \%$ & $0,23 \%$ & $1,18 \%$ & $0,24 \%$ \\
Correct classification & $93,52 \%$ & $96,87 \%$ & $97,62 \%$ & $99,77 \%$ & $98,82 \%$ & $99,76 \%$
\end{tabular}


Table 18: Average Results

\begin{tabular}{r|ccr|cc} 
& LOGIT & & DA & \\
\hline & cut-off & ROC & & cut-off & ROC \\
\hline Sensitivity & $57,33 \%$ & $95,58 \%$ & Sensitivity & $75,25 \%$ & $86,86 \%$ \\
Error type I & $42,67 \%$ & $4,42 \%$ & Error type I & $24,75 \%$ & $13,14 \%$ \\
Specificity & $98,51 \%$ & $91,22 \%$ & Specificity & $94,25 \%$ & $96,39 \%$ \\
Error type II & $1,49 \%$ & $8,78 \%$ & Error type II & $5,75 \%$ & $3,61 \%$ \\
Error rate & $3,78 \%$ & $8,43 \%$ & Error rate & $6,64 \%$ & $4,28 \%$ \\
Correct classification & $96,22 \%$ & $91,57 \%$ & Correct classification & $93,36 \%$ & $95,72 \%$
\end{tabular}


Figure 1: ROC curve CDA vs Logit regression

Canonical Discriminant Analysis

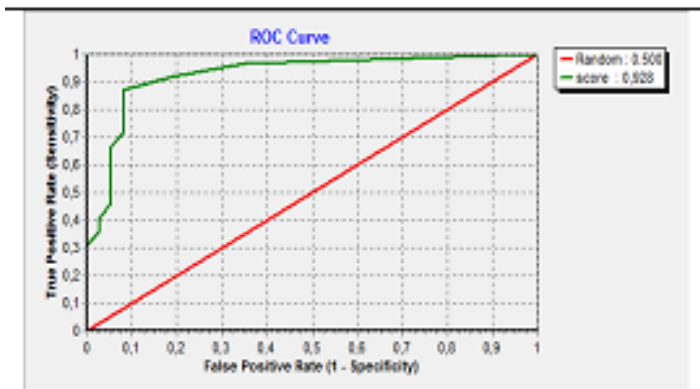

ROC curve of CDA 2008

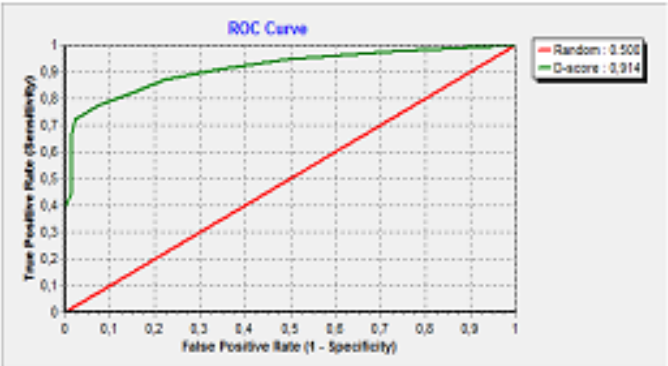

ROC curve of CDA 2009

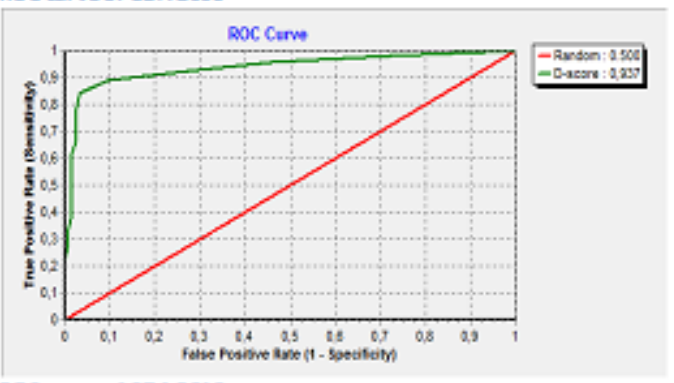

ROC curve of CDA. 2010
Logit

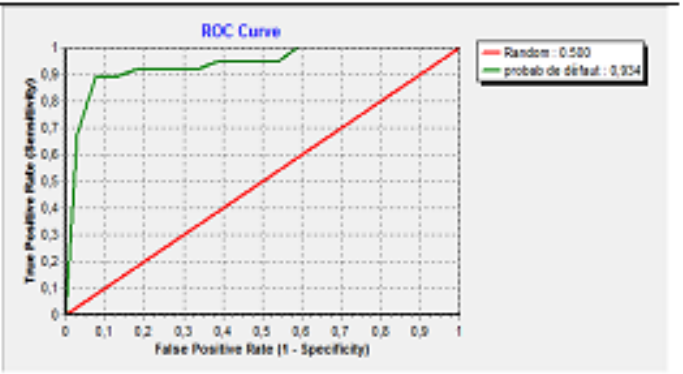

ROCaurve of Logistic Regression 2008

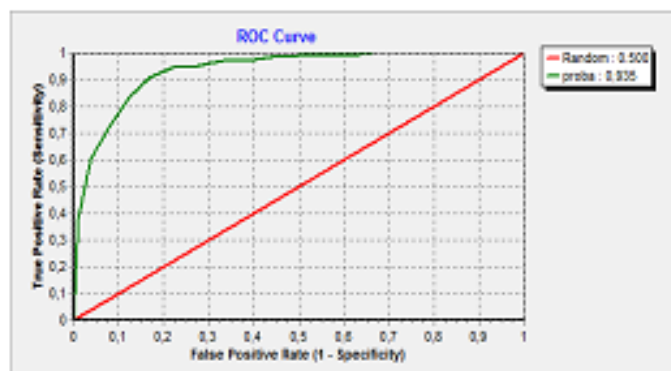

ROCarve of Logistic Regresion 2009

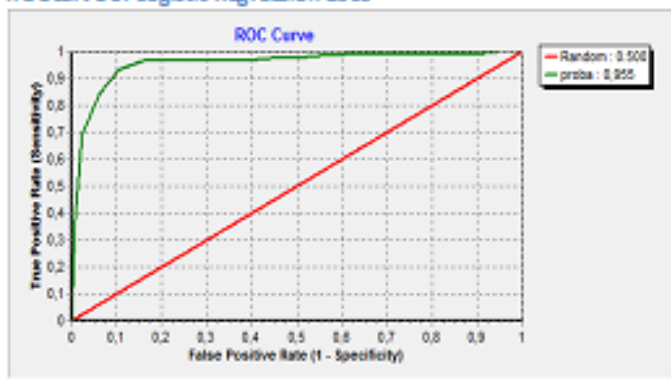

ROCaurve of Logistic Regression 2010

curve1.png 

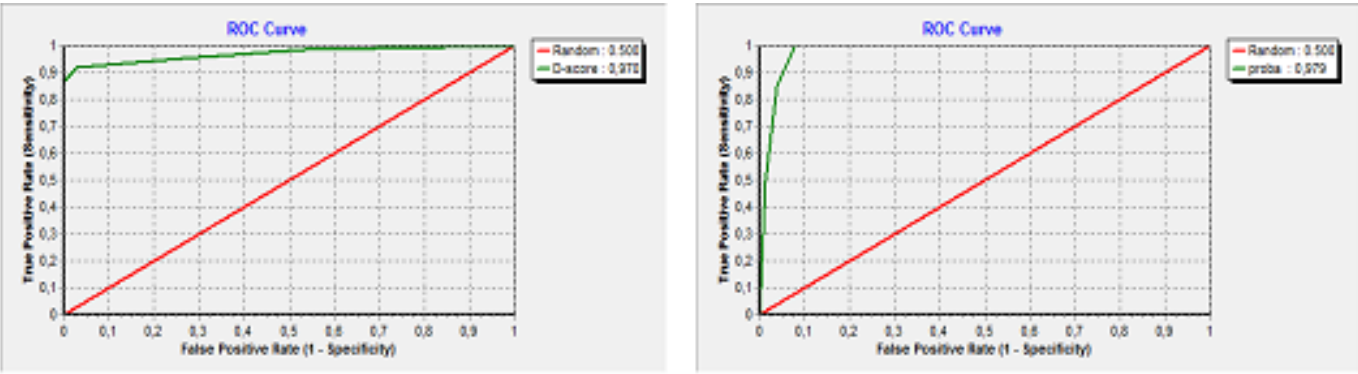

ROC curve of CDA 2011

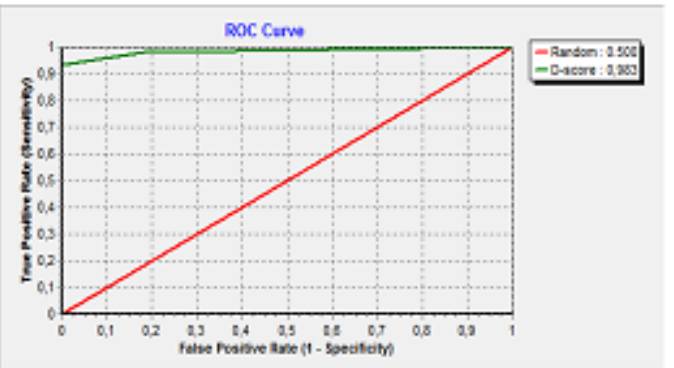

ROCaurve of Logistic Regression 2011

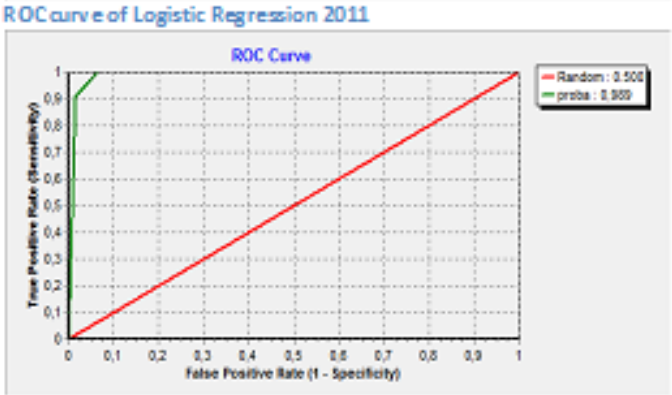

ROC arve of CDA 2012

ROCaurve of Logistic Regreszion 2012

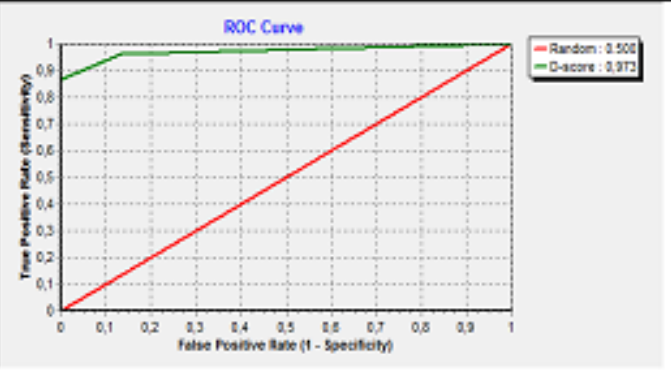

ROC Curve

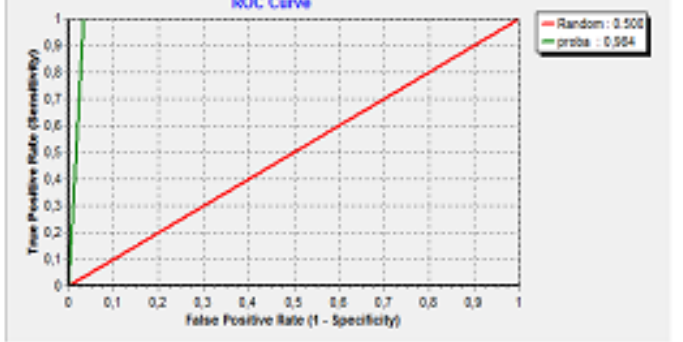

ROC arve of CDA 2013

ROCaurve of Logistic Regression 2013

curve2.png 
Figure 2: Best cut off point that maximizes the sensitivity and the specificity

Canonical Discriminant Analysis

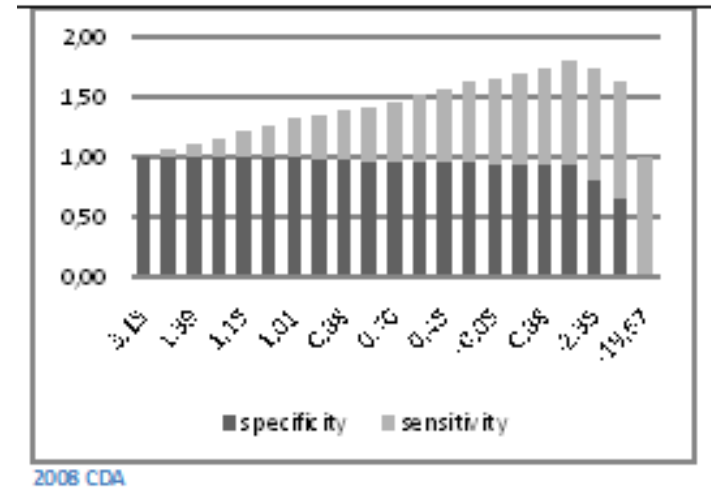

Logit
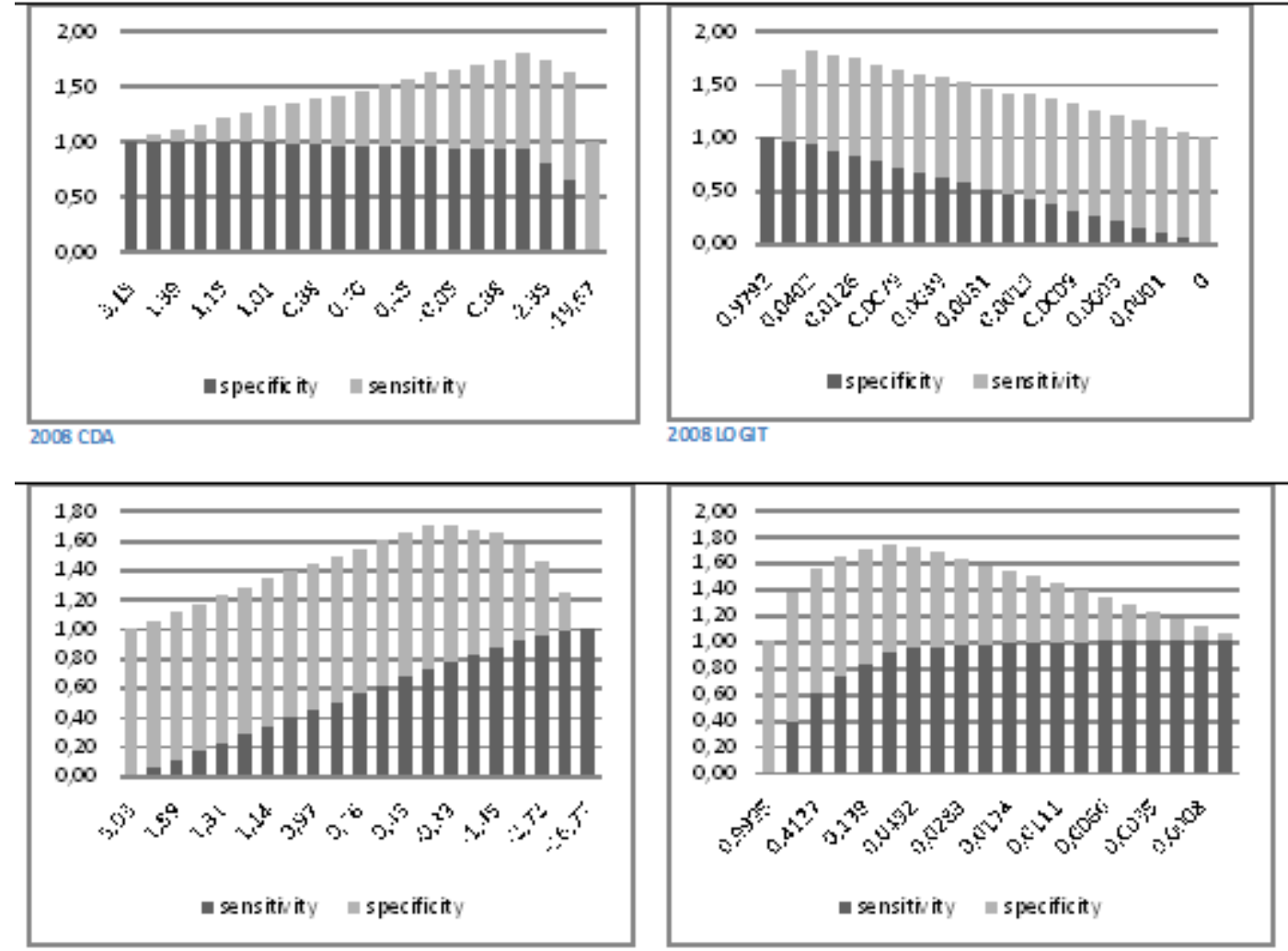

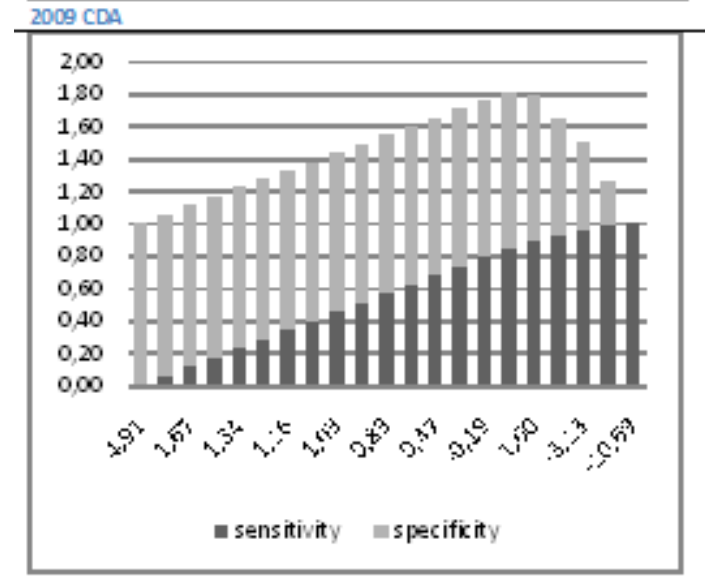

$2010 \mathrm{CDA}$

2009 ம GIT

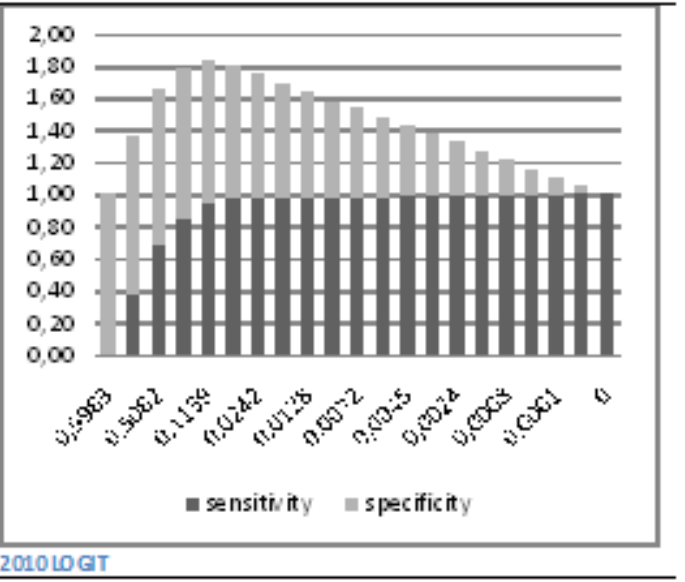

cut-off1.png 


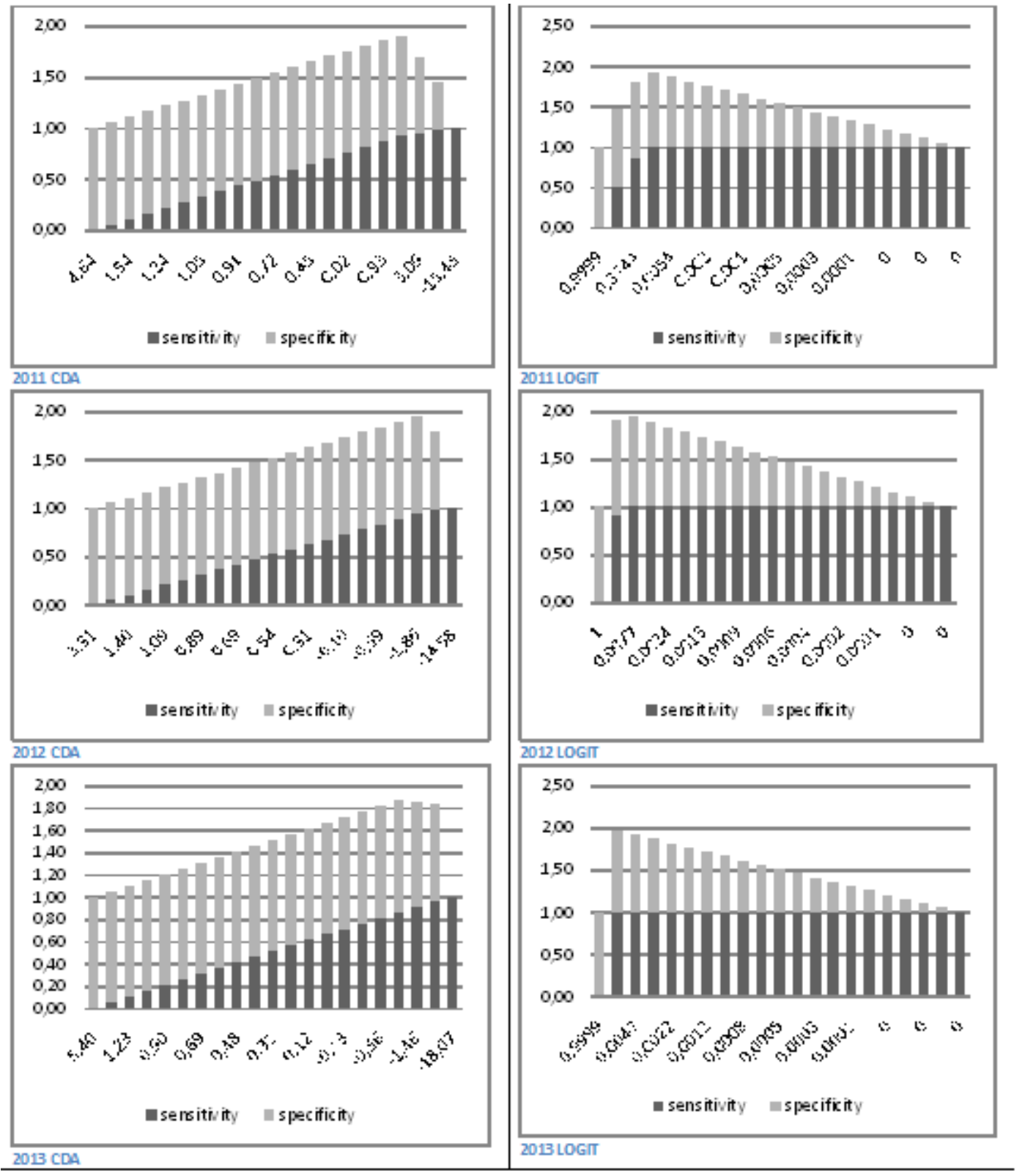

cut-off2.png 
Figure 3: Error type I and II : Logit vs CDA

\section{logistic regression}

nerrortype I Inerror type II

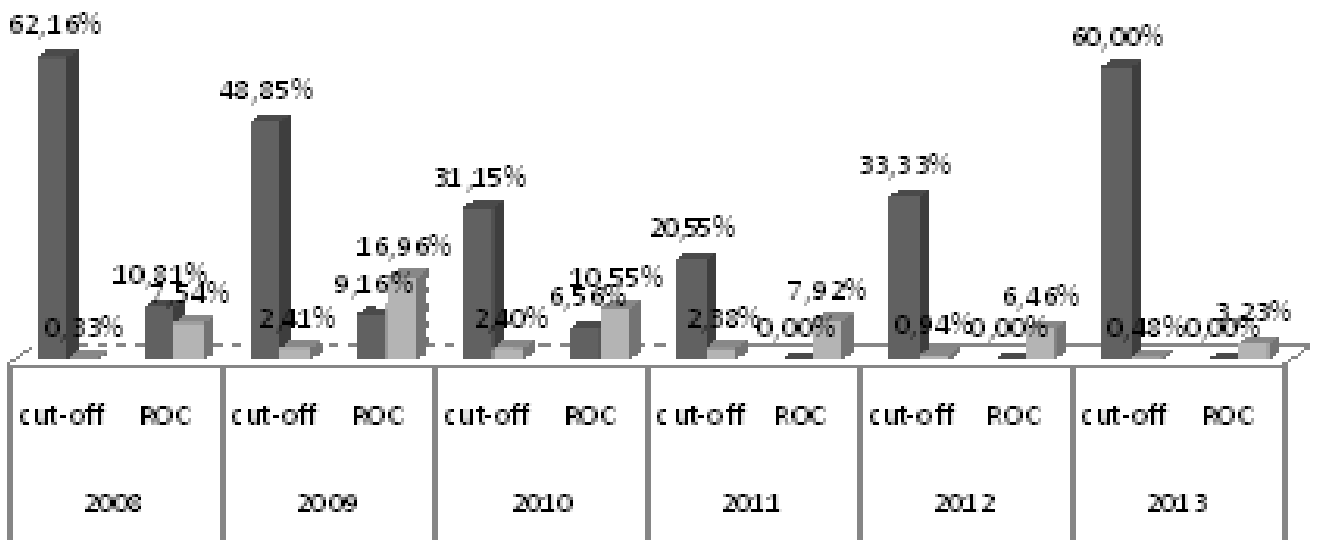

\section{canonical discriminnat analysis}

Eerior type I werror type II

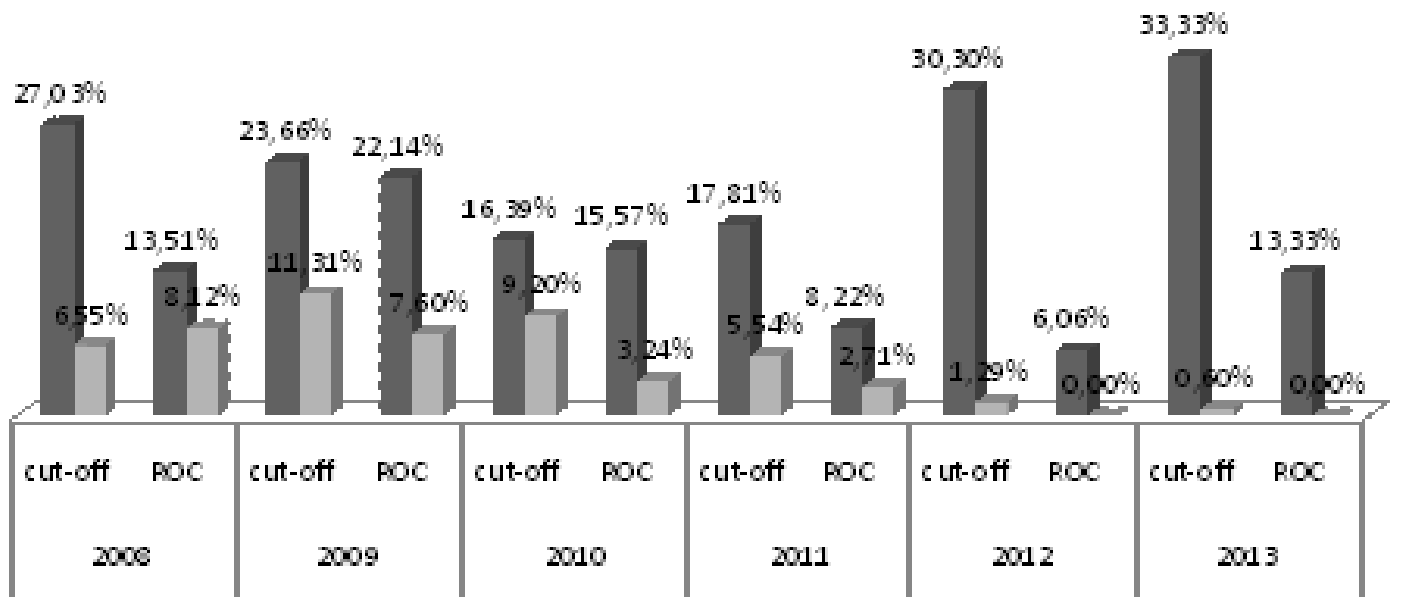

